\title{
The spatial allocation of population: a review of large-scale gridded population data products and their fitness for use
}

\author{
Stefan Leyk ${ }^{1,11}$, Andrea E. Gaughan ${ }^{2,10}$, Susana B. Adamo ${ }^{3}$, Alex de Sherbinin ${ }^{3}$, Deborah Balk ${ }^{4}$, \\ Sergio Freire $^{5}$, Amy Rose ${ }^{6}$, Forrest R. Stevens ${ }^{2,10}$, Brian Blankespoor ${ }^{7}$, Charlie Frye ${ }^{8}$, \\ Joshua Comenetz ${ }^{9}$, Alessandro Sorichetta ${ }^{10}$, Kytt MacManus ${ }^{3}$, Linda Pistolesi ${ }^{3}$, Marc Levy ${ }^{3}$, \\ Andrew J. Tatem ${ }^{10}$, and Martino Pesaresi ${ }^{5}$ \\ ${ }^{1}$ Department of Geography, University of Colorado Boulder, Boulder, CO 80309, USA \\ ${ }^{2}$ Department of Geography and Geosciences, University of Louisville, KY 40292, USA \\ ${ }^{3}$ CIESIN, Columbia University, Palisades, NY 10964, USA \\ ${ }^{4}$ CUNY Institute for Demographic Research, and Marxe School of Public and International Affairs, \\ Baruch College, City University of New York, New York City, NY 10010, USA \\ ${ }^{5}$ European Commission, Joint Research Centre (JRC), Ispra, Italy \\ ${ }^{6}$ Human Dynamics Group, Oak Ridge National Laboratory, Oak Ridge, TN 37831, USA \\ ${ }^{7}$ Development Data Group, World Bank, Washington, D.C. 20433, USA \\ ${ }^{8}$ Environmental Systems Research Institute, Redlands, CA 92373, USA \\ ${ }^{9}$ U.S. Census Bureau, Washington, D.C. 20233, USA \\ ${ }^{10}$ WorldPop, School of Geography and Environmental Sciences, University of Southampton, \\ Southampton, SO17 1BJ, UK \\ ${ }^{11}$ Institute of Behavioral Science, University of Colorado Boulder, Boulder, CO 80309, USA \\ Correspondence: Stefan Leyk (stefan.leyk@ colorado.edu)
}

Received: 21 May 2019 - Discussion started: 6 June 2019

Revised: 23 July 2019 - Accepted: 25 July 2019 - Published: 11 September 2019

\begin{abstract}
Population data represent an essential component in studies focusing on human-nature interrelationships, disaster risk assessment and environmental health. Several recent efforts have produced global- and continental-extent gridded population data which are becoming increasingly popular among various research communities. However, these data products, which are of very different characteristics and based on different modeling assumptions, have never been systematically reviewed and compared, which may impede their appropriate use. This article fills this gap and presents, compares and discusses a set of large-scale (global and continental) gridded datasets representing population counts or densities. It focuses on data properties, methodological approaches and relative quality aspects that are important to fully understand the characteristics of the data with regard to the intended uses. Written by the data producers and members of the user community, through the lens of the "fitness for use" concept, the aim of this paper is to provide potential data users with the knowledge base needed to make informed decisions about the appropriateness of the data products available in relation to the target application and for critical analysis.
\end{abstract}




\section{Introduction}

The distribution and density of human population continues to be a critical component to measuring, mapping and understanding human-environment interrelationships; identifying populations at risk of infectious diseases or disasters; and informing management and policy decisions from local- to global-level initiatives (e.g., Wesolowski et al., 2014; Simarro et al., 2011; McDonald et al., 2011; Jones et al., 2008; McGranahan et al., 2007; Doocy et al., 2007). The traditional form of collecting population data is through a census or registry, and those population counts can be spatially linked to boundary datasets representing enumeration areas (the most basic unit of collected census data) or administrative units in a Geographic Information System (GIS). More recently, an increasing use of fully georeferenced censuses has made building-level mapping more feasible in some countries. However, census data vary substantially across countries with regard to quality, the number and size of enumerated areas, the frequency of data collection and the level of confidentiality depending on detail. The size of census units also varies significantly within countries between rural and urban areas. Thus, to be useful for many analytical purposes, substantial efforts are required to harmonize such enumerated data (de Sherbinin, 2017; Zoraghein et al., 2016; Schroeder, 2007). Since Tobler's "World population in a grid of spherical quadrilaterals" (Tobler et al., 1997) and Liverman et al.'s "People and Pixels" (Liverman et al., 1998), the benefits of gridded population data have been acknowledged. As a consequence, the scientific community has increasingly invested in ways to create global georeferenced data products that help overcome the inconsistencies in census-derived national population data and facilitate their integration with other gridded spatial datasets such as remote sensing data products. This article, a product of the POPGRID Data Collaborative (POPGRID, 2018), describes the variety of gridded population data products that have been created over the past 20 years and is an effort to aid users in better understanding the nature of these products, their qualities and forms of appropriate uses.

There is high demand for modeled gridded population datasets particularly in countries with less detailed or infrequent censuses. These datasets, for example, support land use and urban planning (Dong et al., 2017), measurement of economic development (Nordhaus, 2006; Uchida and Nelson, 2009; Roberts et al., 2017), transportation infrastructure management and rural access (Iimi et al., 2016; World Bank, 2016), resource allocation strategies (Islam et al., 2006; Deichmann et al., 2011), disaster risk mitigation, management and reduction (Ehrlich et al., 2018a; Aubrecht et al., 2016; Gunasekera et al., 2015; Mondal and Tatem, 2012; Taramelli et al., 2010), climate change research (Blankespoor et al., 2017; Dasgupta et al., 2011; McGranahan et al., 2007), sampling design for household surveys (Blankespoor et al., 2018; Thomson et al., 2017), public health campaigns and assessments (Snow et al., 1999; Hay et al., 2004; Jones et al., 2008; Weber et al., 2018; Dunn et al., 2019), and sustainable resource management (Koch et al., 2008; Parish et al., 2012; McDonald et al., 2011) among many other applications ${ }^{1}$. International frameworks for development and sustainability depend on the availability of population data, which are commonly used as a denominator in calculating different metrics and indicators. Such frameworks include the Sustainable Development Goals (SDGs), the Sendai Framework for Disaster Risk Reduction, the UNFCCC Paris Agreement and the United Nations New Urban Agenda, to mention just a few.

The field has seen advances at multiple levels. First, the spatial resolution of underlying census data available for geoprocessing, along with the standards for producing such data (United Nations, 2009), has improved dramatically in many countries since the creation of the earliest gridded population data products such as the Gridded Population of the World version 1 (Tobler et al., 1995; Deichmann, 1996). Second, significant progress has been made through advances in information extraction and classification of populated land area from remote sensing data at various resolutions (Wardrop et al., 2018). The increased availability and spatial granularity of remotely sensed information about topography, vegetation and land cover has been critical to improving the identification of such places that are potentially inhabited and even the estimation of counts of people living there (Frye et al., 2018; Nieves et al., 2017; Pesaresi et al., 2013). Third, the combination of access, increased computing power and greater spatial accuracy in ancillary datasets has provided the basis for methodological advances to redistribute censusenumerated population counts to grid cells at continental and global scales with high accuracy (e.g., Freire et al., 2018) and to create time series of population estimates that can be used to fill in data gaps between national census surveys that are commonly taken at decadal intervals (e.g., WorldPop and CIESIN, 2018).

As a result of these recent developments, there are now several global and continental gridded population datasets that are based on different modeling approaches and input data layers. As might be expected, there are similarities but also important differences among these products, and yet to date there has neither been a systematic review of these various approaches nor a comparison of the corresponding outputs. This represents a serious gap in the literature as these differences can easily lead to misunderstandings or inappropriate use of population grids. The objective of the paper is to fill that gap by helping guide users in forms of appropriate, uncertainty-aware use of the available global gridded popu-

\footnotetext{
${ }^{1}$ The citations listed here are just a few of hundreds of applications that could have been identified. This paper does not aim to be a complete review of the literature or applications of all usages of the gridded data products under review. Links to citations of particular data products are found in Sect. 6 below.
} 
lation datasets in different application areas. Such an assessment is necessary as knowledge of underlying approaches and input data can inform about what each gridded product actually measures. For example, the exposure of a target population to disasters requires a population grid that (1) covers the area of interest, (2) provides a meaningful analytical unit (i.e., the size of the grid cell), (3) warrants the temporal currency needed relative to the time of interest, and (4) estimates the correct target population. ${ }^{2}$ This example demonstrates why applying population grids is not trivial; grids have different characteristics that may affect the accuracy and precision of the analysis but also their suitability in a given context.

The above aspects together provide the essential components to assess the fitness for use of a data product in the context of relative data quality (Tayi and Ballou, 1998). "Fitness for use" is a concept that has often been used to assess the appropriateness of a given spatial dataset for an intended purpose (Agumya and Hunter, 1999; de Bruin et al., 2001; Devillers et al., 2007). Here, this concept will be applied to guide a growing user community in making informed decisions regarding the most appropriate dataset(s) for their intended use by better understanding the characteristics of the available different data products that also include the modeling assumptions behind them. Spatial, thematic and temporal accuracy play a key role in formalizing fitness for use. However, the multidimensionality of accuracy in the case of population grids is further driven by the nature and heterogeneity of the input population data, the use and characteristics of ancillary data involved, and the methodological framework applied to redistribute population counts to grid cells. All these factors will be systematically explored in this article.

This review targets researchers and applied users in the geospatial, demographic, environmental and land use research communities with diverse needs. Section 2 begins with a brief history of population gridding. Section 3 looks at commonalities and differences in methods applied and ancillary data used to produce gridded population data. Section 4 provides an introduction to the data products of interest herein and summarizes the approaches behind the most recently released global as well as some selected regional and national gridded population datasets. Section 5 provides a comparative discussion of several components related to the fitness for use of the different data products. Finally, we list guidelines that can help the user community make informed decisions related to the fitness of a given population data product for their intended use and identify future avenues of work and needed investments in Sect. 6.

\footnotetext{
${ }^{2}$ In the production of gridded population data, the underlying census data are accepted as demographically accurate. While demographers concern themselves with such issues as age heaping (Myers, 1993) or completeness of registrations or census samples (e.g., Potter and Ordóñez, 1976) at the national and first-order administrative level, to the extent that such problems exist (perhaps to an even greater degree) in the fine-grain, underlying spatially refined data, these issues are inherited into the gridded data products.
}

\section{People as gridded distribution: background and} historical development

In the past, mapping population typically entailed linking tabulated population statistics to vector features, such as points (e.g., geographic coordinates indicating city centers) and/or polygons (most notably, administrative units or census enumeration areas). Beginning in the 1990s, a new approach to mapping population distributions emerged, which was to convert population data from irregular vector formats to gridded surfaces composed of regular, standardized grid cells or pixels (e.g., Martin and Bracken, 1991; Tobler et al., 1995; Martin, 1996; Balk et al., 2006; Thomson et al., 2017).

The impetus to grid population data arose soon after the first GIS software packages were developed and as the spatially oriented research community began to use a growing number of gridded biophysical and geophysical data products. Regular grids represented an efficient and consistent data storage format, and the move to gridded data - already in use by the climatological modeling community - was reinforced by the growing array of remote sensing data products that began to appear in the 1970s and 1980s. By gridding population, researchers were able to more easily integrate population count and density data with biophysical data to better understand spatial distributions and components of socioenvironmental systems. Furthermore, by decoupling the data from their original administrative boundaries, populations could then be easily aggregated to different units of interest (e.g., watersheds or climate zones) for spatial and statistical analysis (Balk et al., 2009).

Early efforts to grid populations include an African population grid for UNEP's World Atlas of Desertification (Deichmann and Eklundh, 1991), the NASA Goddard Institute for Space Studies' Global Distribution of 1984 Population Density at $1^{\circ} \times 1^{\circ}$ Resolution (Fung et al., 1991) and Tobler's pycnophylactic method (Tobler et al., 1997), which resulted in the first version of Gridded Population of the World in 1995. These early approaches spread populations evenly across grid cells within input census units, with adjustment effects applied (in the case of the pycnophylactic method) at the unit boundaries. One inherent problem of these early modeled outputs is the existence of aggregation effects that often lead to analytical challenges, as described in the next paragraph. Two concomitant changes helped to partially overcome this inherent problem: first, improvement in the spatial resolution of the underlying population data, and increased computation capacity to use higher-resolution data, have reduced the impact of this problem for many applications. Second, as methods and data availability have progressed, researchers also sought to improve the spatial resolution of population estimates by reallocating populations using ancillary datasets, a spatial refinement strategy known as dasymetric mapping (Semenov-Tian-Shansky, 1928; Wright, 1936), in combination with different statistical methods (e.g. $\mathrm{Wu}$ et al., 2005). Both dasymetric and statistical techniques 
continue to play an important role in gridded population mapping (Mennis, 2009), as discussed below. In addition to such spatial refinement strategies, ongoing efforts also focus on improving the temporal coverage and temporal resolution as well as increasing the variety of population characteristics mapped.

While the development of consistent, comparable grids is what makes gridded data products so useful, there are some important implications that need to be addressed, as should be the case for any geospatial data. Population is not randomly distributed and therefore the allocation and representation of populations will always be subject to aggregation effects. These effects have been described in the geography literature as the modifiable areal unit problem (MAUP) (Openshaw and Taylor, 1981). According to MAUP, the level of aggregation - in this case the census unit or administrative level - and the shape of the reporting units can affect the analysis in ways that are difficult to predict. MAUP is manifested in the flawed assumption of homogeneity of population distributions across census reporting units. The spatial resolution of a gridded population dataset determines the output analytical unit and thus will have implications due to these same aggregation effects after transitioning population counts from vector boundaries to grid cells. In other words, these aggregation-related problems of enumerating data are not eliminated but are propagated into a different data structure through the creation of gridded population data.

As one of the most persistent problems in geographical analysis, MAUP-related research has made significant progress to better understand the sensitivity of analytical results due to changing aggregation levels using synthetic and real-world data (Amrhein, 1995; Steel and Holt, 1996; Flowerdew et al., 2001; Pawitan and Steel, 2006; Wong, 2009; Arbia and Petrarca, 2011; Maclaurin et al., 2015). However, because of this sensitivity, it is important to recognize that MAUP affects the fitness for use of data products for specific analyses in which the spatial precision of population locations is critical. Other implications that affect the quality of population grids have been reported by the data producers, including temporal differences of input and ancillary variables as well as the measurement construct of population that is mapped. While these quality aspects are important to help the user community by guiding general applications, the impact of these aspects on the fitness for use of the data products for specific applications is difficult to measure and not well understood.

\section{Putting people in places: key methods and ancillary data}

\subsection{Methods for population redistribution}

Understanding the fundamentals of the different data integration approaches is an important aspect in evaluating the fitness of any given dataset for specific uses or cases. The process of gridded population mapping requires reallocation of spatial data from source units into target units, usually as a form of disaggregation that can be done through different approaches including various forms of areal interpolation and statistical modeling.

Areal weighting techniques (the simplest form of areal interpolation, also known as proportional reallocation) evenly redistribute source data into target grid cells based on proportions of overlap with no ancillary data input informing the process (Goodchild and Lam, 1980; Mennis and Hultgren, 2006) (Fig. 1a). The source input data may be census-based or other administrative data, and the target grid cell represents a spatial unit which is generally smaller than the source units. An assumption associated with this approach is that the population is uniformly redistributed from the source units to target cells that overlap with the source units. This assumption is a gross simplification as population distributions are not uniform, but the approach is computationally efficient and simple in creating spatially explicit and globally consistent population estimates. Such products are well suited for informing policy-making efforts that do not require fine spatial resolution (Doxsey-Whitfield et al., 2015), or for performing correlation analyses in which endogeneity issues are excluded (e.g., Cohen and Small, 1998). The Gridded Population of the World (GPWv4) product is an example of this approach.

When ancillary data inform the redistribution through areal interpolation from source area to target cell, the technique is referred to as dasymetric mapping (Semenov-TianShansky, 1928; Wright, 1936; Eicher and Brewer, 2001; Mennis, 2003; Mennis and Hultgren, 2006). The ancillary variables, often produced and available at finer spatial detail than the input population data, can be used to develop weighting schemes for reallocating population from the source area to target units depending on existing or assumed relationships between the two. Ancillary variables can include land cover, topography, land use zones, street networks, remote sensing data and more (for details and more examples see Zandbergen and Ignizio, 2010; Nieves et al., 2017; for an overview see Mennis, 2009). For example, redistributing population from a source area (e.g., a census tract) that includes built or developed parts along with forest and agricultural land uses will more heavily weight the built area in redistributing population counts because it is more likely that these areas are populated (Mennis and Hultgren, 2006; Bhaduri et al., 2014). All dasymetric mapping approaches rely on existing relationships between population (e.g., provided by the input census data) and ancillary information (e.g., land cover) that can be exploited to redistribute population to finer spatial units with higher accuracy. More traditional dasymetric approaches vary in the allocation method applied, ranging from binary dasymetric refinement (Fig. 1b, Eicher and Brewer, 2001) to more complex weighting approaches (Fig. 1c) such as intelligent dasymetric mapping (Mennis and Hultgren, 2006). These approaches 
(a) Areal weighting

Unit A, $\mathbf{n = 5 4}$ Unit B, $\mathbf{n =}=36$
\begin{tabular}{|c|c|c|c|c|c|}
\hline 6 & 6 & 6 & 4 & 4 & 4 \\
\hline 6 & 6 & 6 & 4 & 4 & 4 \\
\hline 6 & 6 & 6 & 4 & 4 & 4 \\
\hline
\end{tabular}

(c) Dasymetric: empirically derived weights e.g., land use classes (different grey tones)

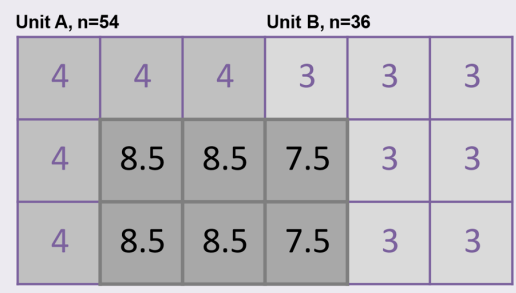

(b) Dasymetric: binary weights Grey: built-up land

Hashed: no built-up

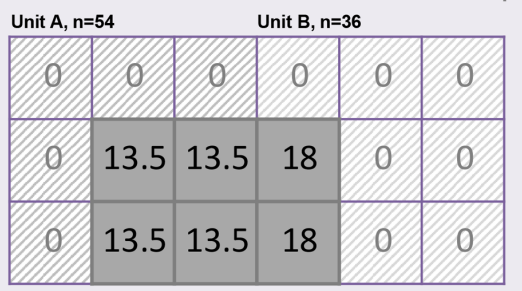

(d) Dasymetric: statistically derived weights (informed by multiple ancillary variables): $\hat{Y}=\alpha+\beta_{1} X_{1}+\beta_{2} X_{2}+\ldots+\beta_{n} X_{n}$

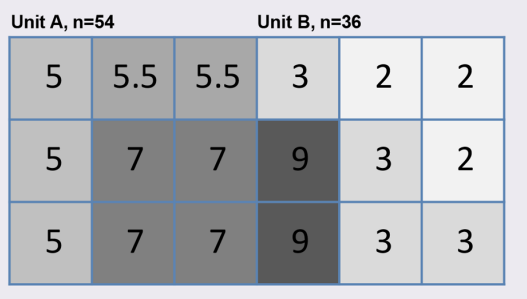

Figure 1. Schematic illustration of different types of techniques for population redistribution or allocation from source to target grid cells: (a) areal weighting as the simplest form of areal interpolation that does not use any ancillary variables; (b) dasymetric mapping using binary ancillary variables that inform and refine areal weighting; (c) dasymetric mapping using varying population weights that may be empirically derived or based on set rules; (d) statistical modeling to estimate relationships that can be used for population modeling. The different grey tones in (b-d) indicate different underlying data informing the areal interpolation process.

differ in the way relationships between population and ancillary variables are derived (i.e., presence/absence based, empirically derived or optimized) to determine weights for different locations to inform the disaggregation of the population totals.

Several statistical modeling approaches have been described in the literature that blur the line between statistical analysis and dasymetric mapping and can be viewed as another means of population estimation, traditionally focusing on the problem of small area estimation (e.g., Birkin and Clarke, 1988; Wong, 1992; Bogaert, 2002), or as a type of dasymetric refinement (e.g., Mrozinski and Cromley, 1999; Leyk et al., 2013) (Fig. 1d). The difference compared to more traditional approaches is that the weights are statistically derived by regressing population counts or densities against various types of predictive variables (Mennis, 2009), derived from ancillary data layers such as density or length of streets (Reibel and Bufalino, 2005), or remotely sensed data (Harvey, 2002; Wu et al., 2005).

More recently, an increasing number of hybrid approaches have been described that explicitly combine the more traditional concept of dasymetric mapping with statistical analytical frameworks. These approaches often rely on machine learning techniques or ensemble prediction that enable the robust estimation of population weights and, in a subsequent step, inform a dasymetric redistribution process (Nagle et al., 2014; Stevens et al., 2015). For example, a statistical model (e.g., a maximum-entropy approach or a random forest model) estimates a population density layer. These es- timated population densities provide a weighting layer that is then used to dasymetrically redistribute total population counts within each source unit to its target grid cells. If there exists a robust settlement layer, then the hybrid approach would use the statistical weighting layer to dasymetrically redistribute the total source zone population counts only to target grid cells that are classified as settlements (Reed et al., 2018). Such hybrid dasymetric approaches have shown promising results when compared to other techniques for producing gridded population maps (Sorichetta et al., 2015; Reed et al., 2018).

\subsection{Ancillary data}

The products included in this comparative review are the outcomes of different data integration approaches to produce gridded population distribution datasets based on different techniques of refinement, zonal statistics, reallocation or inter- and extrapolation. Different ancillary data have been used in slightly different ways to create different population models. As mentioned, all ancillary data have in common that they exhibit some kind of relationship to population that can be exploited in population redistribution models to increase the accuracy of population estimates. These relationships may be of correlative nature, based on empiric rules or even binary. While the literature on population modeling and dasymetric mapping has described a variety of such ancillary variables, the data that can be used in national, regional and global population grid production has to be avail- 
able consistently for large extents, and for different points in time, thus limiting the choices for researchers and data producers. One important class of ancillary data is that of urban land use area or human settlements detections. Figure 2 provides an overview of this type of ancillary data available at different points in time including satellite images (Landsat, MODIS), land cover products and settlement layers (e.g., GHSL or the Global Urban Footprint, GUF+) in relation to commonly available census data. This overview highlights apparent temporal offsets between input population data and some ancillary data. It also emphasizes the high temporal resolution of satellite data, which can have varying quality due to cloud cover and other characteristics and provides the basis for the derivation of abundant ancillary variables including land cover and settlement data.

Table 1 summarizes the input variables, including these land use type and other ancillary data, used to create the different products (also available at https://www.popgrid.org/ compare-data, last access: 15 July 2019); as described earlier, Table 2 provides additional information on the modeling methods used.

\subsection{Different methods and sources of uncertainty}

Figure 3 illustrates, using a region in Kenya, how different ancillary data layers, typically used for population redistribution including roads, land cover, protected areas and topography (Fig. 3b-e) affect the resulting population distribution (Fig. 3f). Different methods described above will employ these variables in different ways and operate under varying assumptions, and they often result in different estimates. Thus, there are expected relationships and trends that can be observed for most population grids. For example, low road density, rough topography and high elevations; the presence of protected area; and nonurban land cover are commonly related to low population densities. However, Fig. 4 illustrates remarkable differences between the population distributions of the data products described in this review for a larger area in Kenya, highlighting the importance of informing the user about critical aspects and characteristics of the different data layers. Note that in Fig. 4a population counts (not density) are rendered per irregularly shaped level 5 census unit. In Fig. $4 \mathrm{c}-\mathrm{h}$, population is rendered per grid cell. Note that the grid cell size is not the same across the panels and is specific to each data product. Within each panel, however, the grid cells have the same extent and can be interpreted as population densities.

It is important to acknowledge the error accompanying the estimation results from such redistribution approaches. This includes uncertainty associated with the original census, the areal aggregation of both the input census data and the ancillary data products (Wu et al., 2005), and the model used to estimate statistical relationships (Nagle et al., 2014; Sinha et al., 2019). Recent research has increasingly stressed the complexity of uncertainty in such applications as well as the difficulty to carry out validation due to the lack of reference data (Mennis and Hultgren, 2006; Zandbergen and Ignizio, 2010). Therefore, error assessments tend to appear mostly in studies in data-rich settings.

The persistent challenges with modeling and validating gridded population datasets especially in data-poor regions have driven more recent initiatives that focus on modeling gridded population from the ground up, relying on microcensus data and geostatistical covariates in a statistical modeling framework (Wardrop et al., 2018). Such techniques, in the absence of reliable or recent census data, leverage advances in computational and statistical frameworks along with increased spatial fidelity of remotely sensed products and advances in global positioning system (GPS)-enabled field survey techniques to produce gridded population surfaces. This type of approach is considered complementary to more traditional, census-enumeration-based efforts.

\section{Current data products, characteristics and availability}

This section summarizes several global data products including the Center for International Earth Science Information Network's (CIESIN) Gridded Population of the World (GPWv4.11) and Global Rural-Urban Mapping Project (GRUMPv1), the European Commission Joint Research Centre (JRC) and CIESIN's Global Human Settlement Population Layer (GHS-POP), Oak Ridge National Laboratory's LandScan; ESRI's World Population Estimate (WPE), and WorldPop's WorldPop datasets. We also reference the History Database of the Global Environment (HYDE) as a gridded data product representing a long-term historical context (i.e., $\sim 12000$ years). Depending on the estimation method applied and ancillary data used, these different data products can be seen as unmodeled, slightly modeled and highly modeled population grids. While the focus of this review is on global population grids, we also discuss a number of country and regional/continental grids, including Facebook and CIESIN's High Resolution Settlement Layer (HRSL), JRC's European GHS Population Grid and the U.S. Census Bureau's country grids (Demobase). Owing to space constraints, we omit gridded population projections such as those developed by Jones and O'Neill (2016). Similarities and differences in these data products are detailed in Table 2. Extended data documentation and visual comparison tools (tables and map services) are available through the POPGRID website (https://www.popgrid.org/, last access: 15 July 2019).

\subsection{Global population data production efforts}

Gridded Population of the World version 4 (GPW4) is a data collection consisting of gridded data products on total population counts and densities and other key demographic variables, globally at a nominal spatial resolution of $1 \mathrm{~km}$ using 


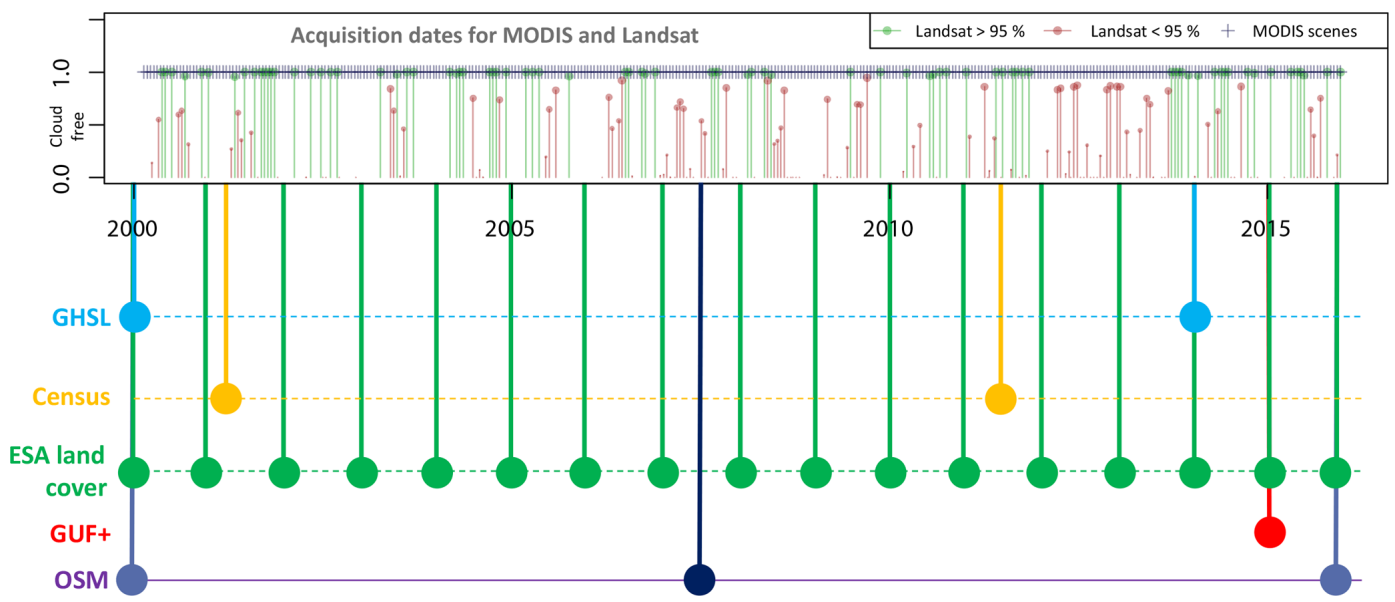

Figure 2. Identification of different ancillary data that inform spatial and temporal interpolation approaches to create gridded population data across scales of interest. Temporal fidelity in the Landsat ( $30 \mathrm{~m}$ resolution; with varying proportions of cloud-free area) and MODIS ( $250 \mathrm{~m}$ resolution) sensors is shown in relation to typical points in time for censuses alongside several derived ancillary data products such as the European Space Agency (ESA) annual land cover data (300 m resolution) and the Global Human Settlement Layer (38 $\mathrm{m}$ resolution) at various publication dates. The Global Urban Footprint (GUF+) exists for one point in time only. Also noted are OpenStreetMap data, vector-based information that is increasingly explored as a possible ancillary data source, which can be acquired anytime and is potentially useful for more contemporary time periods as a static variable; as it is continually evolving, its currency may deviate by region.

Table 1. Summary of input variables used in modeling gridded population globally.

\begin{tabular}{|c|c|c|c|c|c|c|c|c|c|c|}
\hline \multirow{2}{*}{$\begin{array}{l}\text { Gridded } \\
\text { population } \\
\text { dataset }\end{array}$} & \multirow[t]{2}{*}{ Population } & \multicolumn{9}{|c|}{ Ancillary data layers } \\
\hline & & Roads & $\begin{array}{l}\text { Land } \\
\text { cover }\end{array}$ & $\begin{array}{c}\text { Built } \\
\text { structures }\end{array}$ & $\begin{array}{c}\text { Cities } \\
\text { or urban } \\
\text { areas }\end{array}$ & $\begin{array}{l}\text { Night- } \\
\text { time } \\
\text { lights }\end{array}$ & Infrastructure & $\begin{array}{l}\text { Environmental } \\
\text { data }^{\text {b }}\end{array}$ & $\begin{array}{c}\text { Protected } \\
\text { areas }^{\mathrm{a}}\end{array}$ & $\begin{array}{l}\text { Water } \\
\text { bodies }\end{array}$ \\
\hline GPW & $x$ & & & & & & & & $\mathrm{a}$ & $x$ \\
\hline GRUMP & $x$ & & & & $x$ & $x$ & & & $\mathrm{a}$ & $x$ \\
\hline LandScan & $x$ & $x$ & $x$ & $x$ & $x$ & & $x$ & $x$ & $x$ & $x$ \\
\hline GHS-POP & $x$ & & & $x$ & & & & & & \\
\hline WPE & $x$ & $x$ & $x$ & & $x$ & & & & & $x$ \\
\hline WorldPop & $x$ & $x$ & $x$ & $x$ & $x$ & $x$ & $x$ & $x$ & $x$ & $x$ \\
\hline HYDE 1950-2015 & $x$ & & & & & & & $x$ & & $x$ \\
\hline
\end{tabular}

a Protected areas were not masked out, but national statistical offices often assign no data or 0 (zero) to protected areas. ${ }^{\text {b }}$ Climate, topography, elevation.

the World Geodetic System (WGS84) as a geographic reference system (Doxsey-Whitfield et al., 2015). GPW4 includes estimates for the years 2000, 2005, 2010, 2015 and 2020 respectively. Additionally, GPW4 includes vector point data representing the centroids of input census enumeration units, as well as gridded data on land and water area estimates, national identifiers and data quality metrics. GPW4 employs a uniform allocation approach to disaggregate population, which is based purely on the land area of a given pixel (unmodeled; see Table 2). The mean input administrative area can be used as a data quality metric to provide users with guidance as to the effective local resolution of original input population data. Because the size and extent of input census geographies is highly variable, within and across countries, the scale at which GPW4 data should be analyzed differs by region. For example, in the USA, where census blocks are the primary input units, highly localized analysis is appropriate, whereas the coarse input geographies of Libya require aggregations to provincial scales for analysis. Two variants of the population grids are available: those based solely on inputs from the data supplier (typically national statistical offices) and national totals that match the total population estimate of the United Nations' World Population Prospects (2019). Detailed documentation and metadata on nominal resolution and sources of input data are provided. These data are freely accessible and downloadable at http: //sedac.ciesin.columbia.edu/data/collection/gpw-v4 (last access: 15 July 2019). 


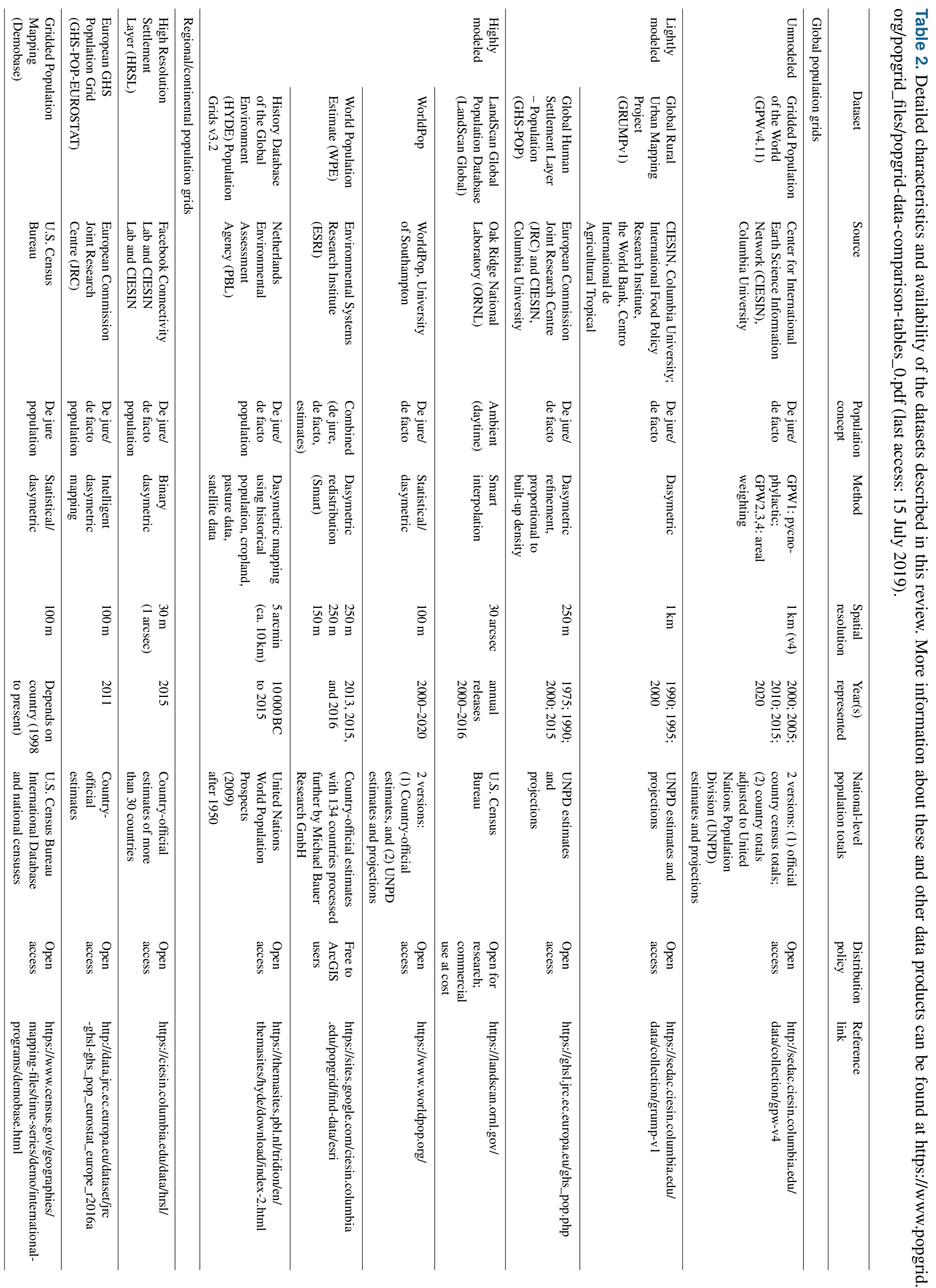



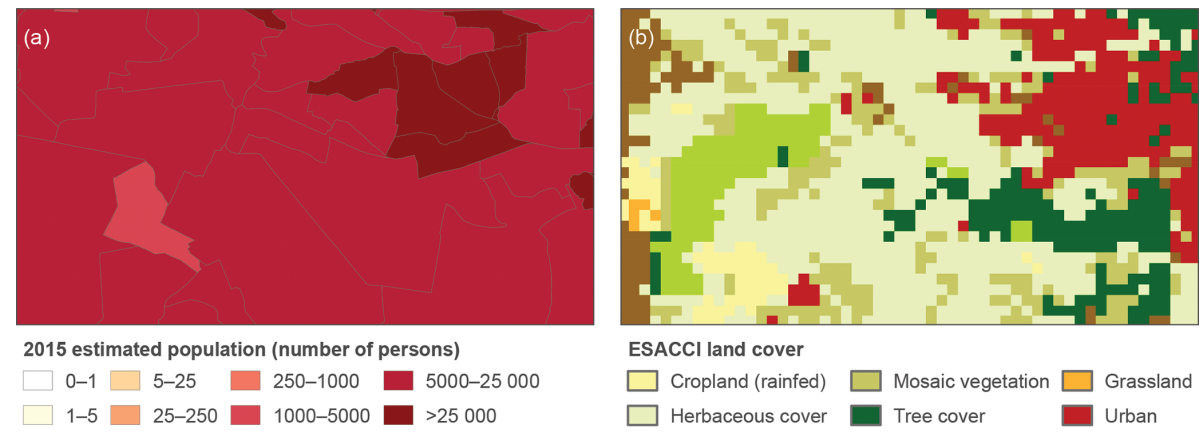

$1-5 \square 25-250 \square 1000-5000 \square>25000$

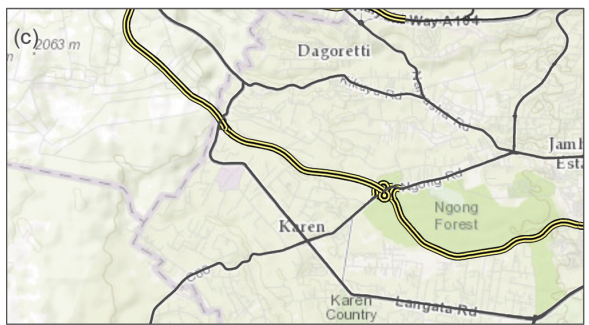

OpenStreetMap roads

= Motorway - Secondary - Trunk

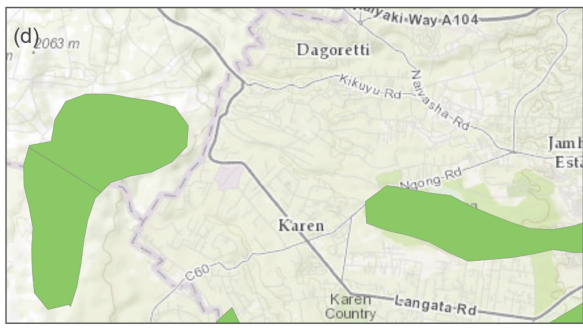

WDPA protected areas

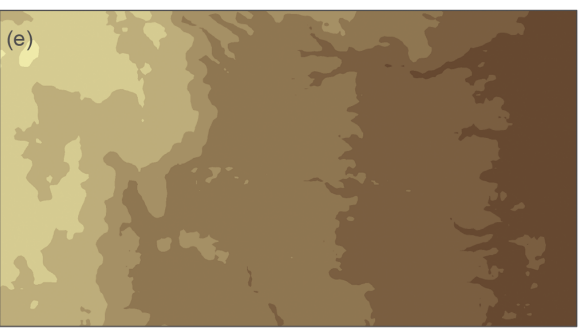

Protected areas
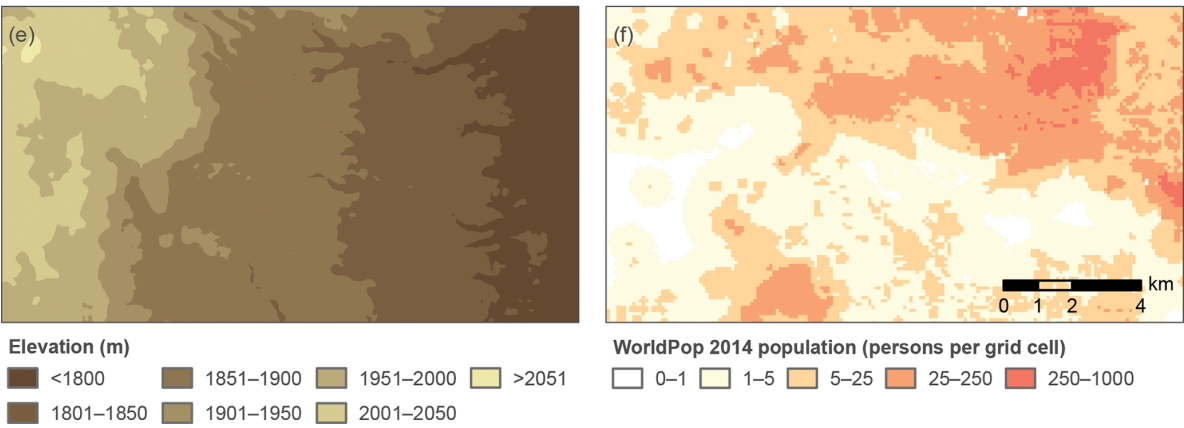

WorldPop 2014 population (persons per grid cell)

$\square$ 0-1 $\square$ 1-5 $\square$ 5-25 $\square$ 25-250 $\square$ 250-1000

Figure 3. A schematic illustration of refinement effects of ancillary data layers on census population data to create gridded population grids at fine spatial resolution for a small study area near Nairobi, Kenya: (a) Kenya National Bureau of Statistics, Population and Housing Census 2009, level 5 population units (Center for Development and Environment, Kenyan Atlas Project) as input; (b) European Space Agency (ESA) Climate Change Initiative (CCI) Land Cover 2015 (300 m resolution); (c) OpenStreetMap major roads (C) OpenStreetMap contributors 2019; distributed under a Creative Commons BY-SA License); basemap is the World Topographic Map (Esri, HERE, FAO, GeoBase); (d) World Database of Protected Areas (March 2019 Release); basemap is the World Topographic Map (Esri, HERE, FAO, GeoBase); (e) Viewfinder Panoramas 3 arcsec digital elevation model; (f) WorldPop 2014 population count (100 $\mathrm{m}$ resolution) as one exemplary population grid created.

The Global Rural-Urban Mapping Project v1 (GRUMP) data collection builds on GPW, also in WGS84 and at a nominal resolution of $1 \mathrm{~km}$, with the explicit aim of capturing urban locations and populations and of distinguishing those from surrounding rural areas. The collection consists of global datasets normalized to the years 2000, 1995 and 1990 that indicate urban settlement points and grids of urban extents, as well as population count and density grids that are lightly modeled, taking the urban location information into account (Balk et al., 2005; Balk, 2009). Using the stablecity light data from the National Oceanic and Atmospheric Administration (Elvidge et al., 1997), GRUMP was the first global database to render urban areas spatially and connect those locations with estimates of population. Although newer nighttime light time-series data are now available (e.g., Elvidge et al., 2017), for a variety of reasons, updates to this exact data product are not presently expected. This is partly due to the fact that the time series does not extend as far back as other possible settlement input layers and that more recent night-lights can be better put to use as an independent proxy for economic activity rather than urban location. The data collection is freely available at https://sedac.ciesin.columbia. edu/data/collection/grump-v1 (last access: 15 July 2019).

The Global Human Settlement Population Grid (GHSPOP) depicts the distribution and density of the total population as the number of people per grid cell $(250 \mathrm{~m}$ spatial resolution) in world Mollweide equal-area projection. Residential population estimates (counts) per smallest cen- 

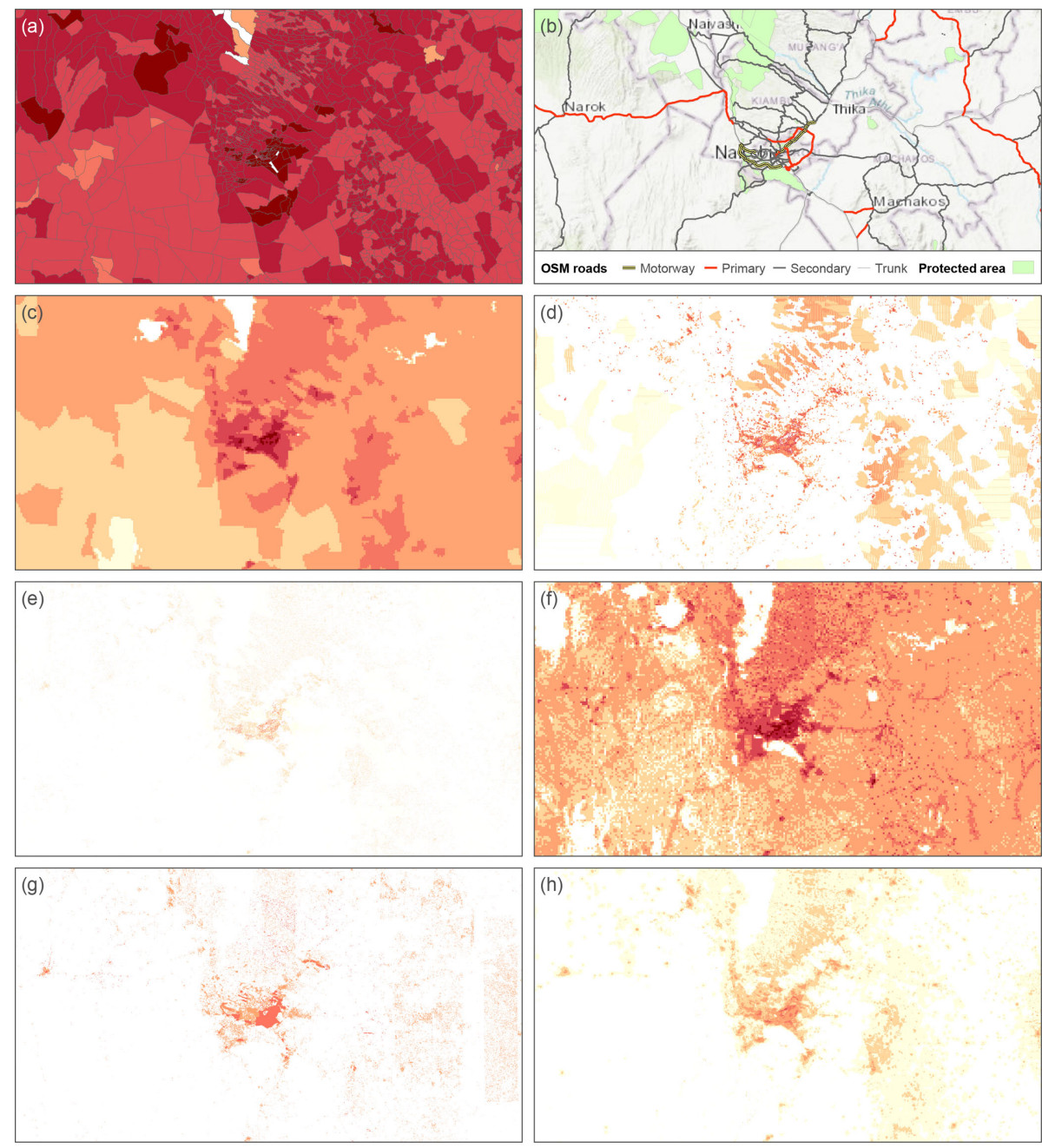

Number of persons: (a) per unit; (c-h) per grid cell

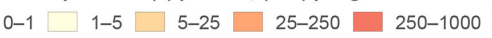

$1000-5000$

$5000-25000$

$>25000$

Figure 4. Illustration of population input, exemplary ancillary data and different outcome data for a larger region around Nairobi, Kenya: (a) Kenya National Bureau of Statistics, Population and Housing Census 2009, level 5 population units (Center for Development and Environment, Kenyan Atlas Project); (b) World Topographic Map (Esri, HERE, FAO, GeoBase) with roads (OpenStreetMap; @ OpenStreetMap contributors 2019; distributed under a Creative Commons BY-SA License) and the World Database of Protected Areas (March 2019 Release); (c) Gridded Population of the World version 4, revision 10, UN adjusted 2015 population count (1 km); (d) Global Human Settlement Layer 2015 population count $(250 \mathrm{~m}$ ); (e) High-Resolution Settlement Layer 2015 population count (30 m); (f) LandScan 2015 population count $(1 \mathrm{~km})$; (g) Esri World Population Estimate 2016 population count $(150 \mathrm{~m})$; (h) WorldPop 2014 population count $(100 \mathrm{~m})$.

sus units available, used also by CIESIN GPWv4 for the years of interest, are disaggregated to grid cells, directly (linearly) proportional to the ratio of built-up areas within a cell to the total cell surface (Freire et al., 2016, 2018). Global mapping of built-up areas was performed through the Global Human Settlement Layer (GHSL) project using Landsat imagery collections for nominal epochs 1975, 1990, 2000 and 2014 (Pesaresi et al., 2013, 2016a, b). The GHSL approach is grounded on the concept that buildings and their agglomerations (i.e., settlements) are nowadays the main visible and direct manifestation of human presence (and activity) on the Earth's surface. GHS-POP aims to constitute a detailed and consistent time series of lightly modeled population distributions that is based on reproducible methods for sustainable data production (Melchiorri et al., 2019) and can be used in policy support in numerous domains (Ehrlich et al., 2018b). These grids are created using open and free input data and are also freely accessible and downloadable at https://ghslsys.jrc.ec.europa.eu/ghs_pop.php (last access: 15 July 2019).

Oak Ridge National Laboratory's LandScan Global represents an ambient (average day/night) population distribution in a $30 \operatorname{arcsec}(\sim 1 \mathrm{~km})$ resolution grid using the World Geodetic System (WGS84) for spatial reference (Dobson et 
al., 2000). LandScan uses census and other geographic data, as well as remote sensing imagery in a multivariate dasymetric modeling framework to disaggregate census counts within administrative boundaries (Dobson et al., 2003; Bhaduri et al., 2002). The final product displays a combination of locally adaptive models tailored to match input geographies and different environmental conditions in countries and regions. The modeling approach, defined as "smart interpolation", uses subnational-level census counts for each country and ancillary datasets, including land cover, roads, slope, urban areas, village locations, and high-resolution image classifications - all of which are key indicators of population distributions. Based upon the spatial data and the socioeconomic and cultural understanding of an area, cells are preferentially weighted for the possible occurrence of population during the course of a day. Within each country, the population distribution model calculates a likelihood coefficient for each cell and applies the coefficients to the census counts, which are employed as control totals for respective areas. The total population for that area is then allocated to each cell proportionally to the calculated population coefficient to compute counts of ambient or average day/night population. LandScan Global is available for download free of charge to the educational community at https://landscan.ornl.gov/ (last access: 15 July 2019).

Esri's World Population Estimate (WPE), initiated in 2014 and produced at the Environmental Systems Research Institute (ESRI), includes population count and density grids at a spatial resolution of $150 \mathrm{~m}$, referenced through the WGS84 geographic coordinate system (Frye et al., 2018). WPE is based on the dasymetric redistribution of human population data enumerated within the most detailed census data available for each country to raster cells using a raster model representing the footprint of human settlement (Frye et al., 2018). The footprint of human settlement is produced using various ancillary data layers. First, base scores are derived through the combination of a $30 \mathrm{~m}$ resolution global classified land cover dataset (MacDonald Dettwiler and Associates, MDA, 2017), road intersection points (HERE 2019, OpenStreetMap Foundation, OSMF, 2015) and populated place points from GeoNames (GeoNames, 2013). The base scores are augmented with texture scores derived from $15 \mathrm{~m}$ resolution Landsat 8 panchromatic images using a rugosity (i.e., terrain roughness) model (Jenness, 2004). The base scores are used to allocate population to WPE cells to create gridded representations of estimates of population counts, population density (number of persons per square kilometer), the likelihood of settlement and confidence scores. WPE is the only commercial product described, available through https://www.arcgis.com/home/item.html?id= 92d3005feb84428a8f85160f2451ec63 (last access: 15 July 2019).

The WorldPop program produces a variety of demographic gridded data products at the global and country scales (Tatem, 2017), including population counts, within
3 arcsec grid cells $(\sim 100 \mathrm{~m}$ at the Equator) in the geographic projection WGS84 (Stevens et al., 2015). Initiated in October 2013, the WorldPop project replaces and merges the regional AfriPop (Linard and Tatem, 2012), AsiaPop (Gaughan et al., 2013) and AmeriPop (Sorichetta et al., 2015) population mapping projects. The main method for producing WorldPop products is a weighted dasymetric approach that relies on a random forest model (Breiman, 2001) to produce a predictive weighting layer for dasymetrically redistributing population counts into gridded cells (Stevens et al., 2015). Individual country outputs from the WorldPop project provide an open access, transparently documented archive of spatial demographic datasets for many regions in the world including Central and South America, Africa and Asia to support development, disaster response and health applications (Gaughan et al., 2013; Stevens et al., 2015; Sorichetta et al., 2015, 2016). In addition, the WorldPop program produces a standardized, temporally and spatially consistent set of gridded products at the global scale. These freely available datasets include the input population data and covariates used in model prediction (Lloyd et al., 2017), annual gridded population count datasets also structured by 36 age and sex classes from 2000 to 2020, and grid cell area estimates that can be used to derive gridded population density datasets. All data can be downloaded from https:/www.worldpop.org/ project/list (last access: 15 July 2019).

The History Database of the Global Environment (HYDE) includes maps of historical estimates of total, urban and rural population, population density and built-up area at a spatial resolution of $5 \mathrm{~min}$ longitude/latitude, provided in decimal degrees. HYDE covers a time period from 10000 before Common Era (BCE) to 2015 Common Era (CE) and is described as an internally consistent combination of historical population estimates and allocation algorithms with time-dependent weight maps for land use (Klein Goldewijk et al., 2010, 2011, 2017). For the period prior to 1950, historical input population estimates were taken from the general literature and supplemented with the subnational population numbers and country-specific sources to build time series for each province or state of every country. For the period after 1950, the underlying input data are based on 1950-2015 population estimates from the United Nations World Population Prospects (2008 revision) as well as land cover and land use data products. All data can be downloaded from https://doi.org/10.17026/dans-25g-gez3 (Klein Goldewijk, 2017).

\subsection{National and regional/continental population data production efforts}

It is imperative for a review of existing global population data products to also reference production efforts at national, regional or continental scales that often make use of more detailed input data but are based on similar methodological frameworks. Such country- and regional-level products 
are often created for specific purposes, which may influence the decision rules applied for their creation. Often these data products are based on more up-to-date ancillary and input population data and thus may provide pointers for future global population data creation once those ancillary data could become available worldwide.

For example, Facebook Connectivity Lab and CIESIN's High Resolution Settlement Layer (HRSL) provide estimates of human population distribution in 33 countries in Central and South America, Africa and Southeast Asia, at a resolution of 1 arcsec (approximately $30 \mathrm{~m}$ ), in the geographic projection WGS84 for the year 2015. Machine learning techniques are used to identify potentially populated areas (settlement) using very high resolution satellite imagery. Proportional allocation is then applied to redistribute population from recent census data onto grid cells identified as settlement extent (Tiecke, 2016; Tiecke et al., 2017). This data production effort was driven mostly by Facebook's interest in locating people in remote areas of developing countries such as Burkina Faso, Ghana, Haiti and Sri Lanka, who may be in need of internet access, and is available from https://www. ciesin.columbia.edu/data/hrsl/ (last access: 15 July 2019).

Developed by the European Commission for the purpose of producing the most detailed possible population grid for policy analysis and support, the European Global Human Settlement (GHS) population grid represents the distribution and density of total residential population, expressed as the number of people per grid cell $(100 \mathrm{~m}$ spatial resolution) in equal-area projection (LAEA ETRS89) for 43 countries and territories in 2011. Intelligent dasymetric mapping (Mennis and Hultgren, 2006) was employed in order to disaggregate best-available census data for each country (vector grids or census tracts) to built-up areas as mapped by the European Settlement Map 2016 (Ferri et al., 2014; Florczyk et al., 2016) and weighted by enhanced land use/cover data from a refined Corine Land Cover map where available (Freire and Halkia, 2014). For eight countries, population grids were originally modeled at $10 \mathrm{~m}$ spatial resolution and then aggregated to $100 \mathrm{~m}$ grid cells. This data product is freely accessible and downloadable at http://data.jrc.ec.europa.eu/dataset/jrc-ghsl-ghs_pop_ eurostat_europe_r2016a (last access: 15 July 2019).

The U.S. Census Bureau has developed gridded Demobase population maps at $100 \mathrm{~m}$ resolution, in the geographic projection WGS84, for selected countries including Haiti, Pakistan and Rwanda (e.g., Azar et al., 2010, 2013), as well as maps of subnational population by age and sex within administrative areas for various points in time since 1998. The Census Bureau has invested in efforts to provide data on population patterns by administrative areas and grid cells for various regions with a focus on improving the availability of detailed population maps in regions likely in need of humanitarian relief and disaster assistance from external partners (U.S. Census Bureau, 2018). Data inputs include census data from every country and territory that conducts a census; demographic surveys; maps of administrative boundaries from national and international mapping agencies; high- and medium-resolution satellite imagery; and a range of ancillary layers such as land cover, road networks and elevation. Both Demobase gridded data and administrative-area-based subnational datasets are freely accessible and downloadable via links at https://www.census.gov/programs-surveys/ international-programs/about/global-mapping.html (last access: 15 July 2019).

\section{Different populations or different data? A fitness-for-use perspective}

The process of creating gridded population products redistributes population estimates from census or administrative areas to grid cells, conditional on where human populations and settlements may be located. The nature, quality and accuracy of the input population data, the characteristics of the output gridded population dataset, the properties of the ancillary data used, and the implications of the methodological approach applied for population allocation and redistribution are all important determinants of spatial data quality in general (FGDC, 1998; Guptill and Morrison, 2013) but also help to shed light on the relative data quality of each of the population grids described in this review. While data quality and its reporting in standardized metadata has been the focus of much research in the last decades, the discussion of relative quality or fitness for use of spatial data has received less attention (see Devillers et al., 2007, 2010; Ivánová et al., 2013). Since the described population grids show fundamental differences, the question of whether a data product is fit for a given purpose is of high relevance. Thus, in this section, we discuss several determinants (not an exhaustive list) that aid the data user in the assessment of the data product's fitness for use relative to the target application. We briefly discuss data-related aspects including scale, currency and semantics, as well as modeling and processing-related implications for uncertainty. We address them separately, but the reader may be reminded that all those relative quality aspects have to be understood to be interrelated as one can affect all others. We will also address the problem of validation of large-scale population grids.

\subsection{Data aspects of relative quality}

The accuracy of the input census/population data and ancillary data includes thematic, spatial and temporal accuracies, which contribute to the level of uncertainty of the final data product. For this reason, the user needs to consider and understand what kind of data are input to a certain data production process. For census data, the completeness of coverage, the margin of error (if sampled), the time period the census is taken and the positional accuracy of the boundaries are measures that can be used but might not be always known, and the data need to be used with caution. This kind of knowl- 
edge is important to reflect when using population grids in a given region (e.g., Tatem, 2014). With regard to the ancillary data, needless to say, the quality of the final population grid depends on the quality of the ancillary data used for redistributing population counts. Apart from the existence and strength of the assumed relationship between population and ancillary variables (Nieves et al., 2017), the accuracy of these spatial layers themselves is critical for the accuracy of gridded population estimates. For example, the classification accuracy of built-up or developed land layers that are used to redistribute census counts to different regions tends to be lower in rural than in urban settings (Wickham et al., 2013; Leyk et al., 2014, 2018; Uhl et al., 2018) but can also vary across larger regions and countries. The quality of remotely sensed ancillary data also depends heavily on the characteristics of the instrument (optical daytime, optical nighttime or radar) and the processing algorithm (e.g., Small et al., 2005; Potere et al., 2009; Pesaresi et al., 2016b; Esch et al., 2017). Such differences propagate through to strongly influence the accuracy of the final population data product and may cause overor underestimations in different subregions. Knowledge of such issues would be critical for the data user if population estimates in different regions are compared with each other. Due to the nature of the input and ancillary data, these accuracies translate into aspects of scale, currency and semantics critical for evaluating the fitness for use of the final population grids as discussed below.

Scale. Since input data are typically enumerated counts, issues due to spatial aggregation including the MAUP (Openshaw, 1983), as the geographical manifestation of the ecological fallacy (Piantadosi et al., 1988; Waller and Gotway, 2004), are one of the main sources of the unknown. Differences in granularity of the input (census) data across different regions or countries must be taken into account since the same population redistribution model may perform very differently under different circumstances due to possible scale effects. In using the final population grids, the grid cell, defined by the spatial resolution (that is, cell size; Table 2), would often be assumed to define the analytical scale (Montello, 2001; Cao and Lam, 1997). The user would often attempt to model a certain process or phenomenon of interest, but often there is a mismatch between this operational scale (e.g., Montello, 2001; Maclaurin et al., 2015) and the analytical scale. However, it is imperative for the user to understand that due to the difference between input population data (i.e., source unit) and output grid cell (i.e., target unit) granularity this assumption may be fundamentally flawed and result in either oversampling or generalization. For example, if the analysis is intended to be conducted at the neighborhood scale, population estimates provided in grid cells of 150 or $250 \mathrm{~m}$ appear to represent meaningful target units. If these input data were at the census block or tract level, the grid cell size would represent an appropriate proxy and can be used as a valid analytical unit at the intended target scale. If, however, the input data originated from large administrative units (e.g., district- or county-level source units) there would be a significant offset between input and output. In such cases, the user would face a higher risk of using oversampled population estimates that might result in higher degrees of local inaccuracy.

Creating equivalencies over time of finely resolved census units is challenging even in vector format; this problem is not necessarily abated when transforming vector data to grids. Differences in embeddedness of the population grid cells within census boundaries (when the census units are intrinsically larger than the average grid cell size) also have implications for subsequent analysis using, e.g., multilevel models over large areas and can become even more problematic if the census boundary-grid cell relationship changes over time, thus impeding the creation of reliable population trajectories of place. To complicate matters, if ancillary data are used to redistribute population (e.g., to built-up portions of the source unit) based on existing relationships, such scale-related problems may be mitigated to some degree. In addition, variation in how a model is trained or the units selected to build the estimation model will influence the final gridded distribution (Sinha et al., 2019). For example, if census data from one region or country are very coarse, a model built based on finer-resolution data from a neighboring region and then applied to the region of interest can be more accurate (Gaughan et al., 2015). Thus, scale effects are inherent to each of the described population grids at different degrees and represent a geographically varying characteristic depending on the granularity of the input data, the strength of the associations between population and ancillary data, and the resolution of the output data. These effects need to be interpreted in the context of the target scale of the intended analysis, and consideration should be given to the type of scaling needed to produce a given grid. For the interested reader, Ge et al. (2019) provides a comprehensive review on scaling considerations when working with geospatial Earth science data.

The currency of the data represents another important issue. In a few instances, underlying census data are old (e.g., in Haiti) or the period between censuses is more than 10 years. While some of the ancillary data are more or less constant over the near term (e.g., water bodies and permanent ice), there may also be temporal mismatches between population data and any of the intrinsically time-varying ancillary data layers (Fig. 2). For example, it may be unknown whether a given built-up land grid cell has been developed at the time the census has been taken. Such temporal offsets may be critical if the assumption for the intended application necessitates a high degree of temporal agreement (currency). This form of uncertainty is difficult to handle and can be further complicated by differences across regions and countries. In response to this, few efforts (e.g., WorldPop and GHS-POP) ensure the use of temporally implicit or invariant ancillary data in the modeling process (Gaughan et al., 2016) (Table 1). However, even under those conditions, there might still be 
underlying issues for projecting forward/backward from census data for a target year of interest. The user is well advised to understand the gridded population estimates as approximations over a period of time and avoid flawed assumptions of high currency in a given analysis.

Semantics. As mentioned before, what the population modeled represents can be very different among data products. This meaning can even be different within one product if, e.g., the census input data account for different population concepts or population groups in different regions or countries. For example, the population estimate might refer to de jure (or legal) populations vs. de facto (or present) populations, and using the one over the other product would possibly result in dramatically different results. The user has to be aware that data on resident populations as provided by censuses are themselves a convention, whose distribution never occurs at any moment in time (de jure census population) or if it does occur (de facto, location at the time of the census) that distribution may not be representative of a different situation or in the medium/long term (i.e., a year): the concept of usual residence. Most of the global population data products use a nighttime/usual residence (de jure) concept or mostly rely on underlying data that use a de jure concept, with LandScan being the notable exception. Thus, the user is well advised to be aware of the meaning of the populations modeled in the population grid in question to avoid such misinterpretations, as indicated in Table 2. The aspects of scale mismatch described above can further add to semantic differences since, due to such aggregation effects, different populations may be modeled. Thus, these implications have to be understood by the user, spatially and semantically, and caution is advised when interpreting analytical results.

\subsection{Processing- and model-related implications of uncertainty}

Regardless of the approach of choice employed for data production, all efforts described in this review do carry out some form of data conversion (e.g., vector to raster) and data integration (reallocation or resampling). The different population grids described are based on varying levels of modeling intensity (unmodeled, lightly and highly modeled) as indicated in Table 2. However, any such data processing step will propagate uncertainty in some way and have consequences for the quality of the outcome data and the subsequent analyses, depending on the input data quality as described above. For example, if large census units (e.g., counties or districts) in vector format are converted to grid cells (rasterization) of fine spatial resolution (e.g., $150 \mathrm{~m}$ ), while there is a clear scale effect to be addressed (see above), the resulting population estimates may differ dramatically for different redistribution models applied that may or may not use ancillary data. The data user needs to be aware that existing uncertainty is not eliminated by applying certain models or integrating different data sources. However, through the process of data integration we may be able to improve the accuracy based on spatial refinement strategies such as dasymetric modeling (Mennis, 2009).

GPW, GHS-POP and HYDE do not employ statistical methods to produce their grids, and thus traditional metrics of uncertainty are not available. Because fine resolution inputs reduce errors of aggregation, GPW reports the number of input units per country used in the gridding process. Nevertheless, errors may persist in countries with highly variable input units. For example, Sahelian countries have finely resolved units for densely populated areas but very coarse units for sparsely populated regions.

The specific model applied to reallocate population counts and densities, which can be empirical or statistical, will always have some error. This error relates to the estimated relationship between population and ancillary variable and not to the final population estimate which also may incorporate uncertainty due to error in the input population data or ancillary data. When the modeling process is statistical or hybrid such as in the case of the WorldPop, LandScan and WPE, estimates of such model errors (e.g., standard error of regression coefficients, prediction error) can be derived as a by-product of the modeling process. To fully understand the quality of a population grid, the error of the applied model needs to be evaluated. Highly accurate ancillary data are not useful if the relationship to population is weak or the model applied inappropriate, and thus the model predictions are unreliable (e.g., low $R$ squared, or deviance explained). Such prediction errors are often assessed in comparison to alternative models but are hard to quantify in the absence of validation data. To complicate matters, the same model might perform very differently in different geographies or under different environmental conditions, an effect known as spatial nonstationarity or spatial variation of the target relationships (Fotheringham et al., 1996). Such variations will further affect the model predictions if left unaccounted for.

\subsection{Validation challenges}

Validation of population data has always been a challenge, simply because validation data at fine resolutions are rarely available and, even when available, may exist at different time periods or confidentiality rules may limit their use in order to not expose individual- and household-level information. Access to such confidential data is only possible with special permission or sworn status and, even then, often the demographic data are only a sample of the whole population. These challenges can be very different between countries, and thus a validation that may be possible in one country does not necessarily translate to another location. For example, Tiecke et al. (2017) compare the locations of the population grid to the GPS coordinates of the nationally representative sample of almost 12000 households interviewed for a survey in Malawi. While a true validation of the gridded output remains a challenge, it is possible to internally test the 
accuracy of the modeling approaches (Gaughan et al., 2015; Sorichetta et al., 2015; Reed et al., 2018). Such an assessment can be done when different levels of census input data are available for use in a model. The approach leverages the coarser level data in different modeling approaches and then compares the gridded outputs to the finer level census data to determine how well and plausibly populations were distributed.

Validating ancillary data may have its own challenges. However, the existence of new, more detailed reference data in some regions (e.g., parcel data, crowdsourcing data) has helped to make progress in evaluating land cover data and built-up land layers, which is key to most of the described population grids (See et al., 2015; Leyk et al., 2018; Leyk and Uhl, 2018). In general, depending on the level of land development and land use patterns in the region of interest, different products may serve the intended purpose differently.

\section{Data availability}

The above described data products and their characteristics including the underlying population concept, method, resolution, points in time, the source for national-level population statistics used and reference links to access the data can be found in Table 2 and in Table 3. All of these population grids are open access except two that have some restrictions. The different data producers host the data in different ways, typically using internal servers and data repositories. Summaries and links to the various data repositories can be found at https://www.popgrid.org/, facilitating access to, documentation and comparison of different data products. As mentioned before, the user can also find visual comparison tools (outputs as tables and through map services) that provide effective ways to perform visual analytics and identify differences in patterns of population distributions exhibited by the different data products.

\section{Fit for use or not fit? Concluding remarks and future work}

The different critical elements described above all have some impact on the fitness for use as a measure of relative data quality. Despite the importance of data quality, it does not receive the attention it deserves, in part because comparative measures may be difficult to conceive, derive or quantify. Furthermore, such assessment also importantly depends on the application of interest. The different aspects above have to be seen in context and considered interrelated. Different analytical and data processing steps such as conversions or data integration do not cause isolated uncertainties, but through all those steps uncertainty can be propagated and thus becomes difficult to control and account for.

Whether or not data are fit for an intended use is not based on standardized measures nor is it well understood as to what the concept of fitness for use actually entails. Often it is at the discretion of the data user to decide whether the use of a given data product is appropriate or not, particularly in the age of open public data and open science. Based on the above discussion, there are a few guidelines that, in general, can help a user make informed decisions related to the fitness of a given population data product for their intended use:

1. How important is spatial refinement of the population grid to be used? In the last 20 years, considerable attention has been paid to the spatial refinement of gridded population estimates. Some applications such as estimation of populations at risk of seaward natural hazards benefit substantially from these improvements. Other applications such as some climate scenario modeling do not require such finely resolved data as information on the general spatial distribution of population at moderate resolution would be sufficient.

2. Does the analysis focus on urban populations? Closely related to the above concern, if the aim of the analysis is to examine urban population distribution as opposed to rural population, one would be better off using a dataset for which information on human settlements or urban extents (e.g., in GHS-POP and GRUMP) has been used in the modeling. Urban land tends to be concentrated and can be clearly distinguished from the surrounding areas in remote sensing images, and thus settlement data products (or other measures of urban extent) are effective in spatially refining population data along an urban gradient that will most likely improve the spatial precision of resulting estimates (though there is always the possibility that they will overconcentrate population in built-up locations). In contrast, data products that do not include such refinements tend to underestimate urban population. Data with extremely high resolution may mitigate such effects even if no settlement data were involved in the data production.

3. What is the target population for the question at hand? Questions aimed at understanding long-term population change are likely to be well served by the use of population grids that represent nighttime, residential population. In other instances, however, for example on emergency response, one may need to know where populations are likely to be during the daytime or rely on an ambient population concept and thus would be better served by data products that incorporate that concept in the modeling process.

4. Is the population grid being used to model other outcomes? If so, and if that outcome may be one of the ancillary variables (or one closely linked to it) used in the production of the population grid, one needs to select a population grid that is not endogenous to the question at hand. For example, if the goal of the analysis is 
Table 3. Attribution table. Gridded population data collections described in this review article, years covered, digital object identifiers and reference links. This review covers sources and versions available as of May 2019.

\begin{tabular}{|c|c|c|c|c|}
\hline Data collection & Year(s) & $\begin{array}{l}\text { Population } \\
\text { themes }\end{array}$ & $\begin{array}{l}\text { Digital object identifier } \\
\text { (DOI) }\end{array}$ & Reference link \\
\hline Gridded Population & $2000 ; 2005$ & Persons & $\begin{array}{l}\text { https://doi.org/10.7927/H4JW8BX5 } \\
\text { (CIESIN, 2018a) }\end{array}$ & https://sedac.ciesin.columbia.edu/data/ \\
\hline of the World & $2010 ; 2015$ & UN WPP-adj. & $\begin{array}{l}\text { https://doi.org/10.7927/H4PN93PB } \\
\text { (CIESIN, 2018b) }\end{array}$ & collection/gpw-v4 \\
\hline \multirow[t]{2}{*}{ (GPWv4.11) } & 2020 & Pop. density & $\begin{array}{l}\text { https://doi.org/10.7927/H49C6VHW } \\
\text { (CIESIN, 2018c) }\end{array}$ & \\
\hline & & UN WPP-adj. & $\begin{array}{l}\text { https://doi.org/10.7927/H4F47M65 } \\
\text { (CIESIN, 2018d) }\end{array}$ & \\
\hline $\begin{array}{l}\text { Global Rural-Urban } \\
\text { Mapping }\end{array}$ & $1990 ; 1995$ & Persons & $\begin{array}{l}\text { https://doi.org/10.7927/H4VT1Q1H } \\
\text { (CIESIN et al., 2011a) }\end{array}$ & https://sedac.ciesin.columbia.edu/data/ \\
\hline Project (GRUMPv1) & 2000 & Pop. density & $\begin{array}{l}\text { https://doi.org/10.7927/H4R20Z93 } \\
\text { (CIESIN et al., 2011b) }\end{array}$ & collection/grump-v1 \\
\hline $\begin{array}{l}\text { LandScan Global } \\
\text { Population Database } \\
\text { (LandScan Global) }\end{array}$ & $\begin{array}{l}\text { annual: } \\
\text { 2000-2016 }\end{array}$ & Persons & $\begin{array}{l}\text { NA; data download at } \\
\text { https://landscan.ornl.gov/landscan-datasets } \\
\text { (last access: } 20 \text { May 2019) }\end{array}$ & https://landscan.ornl.gov/ \\
\hline WorldPop & $2000-2020$ & Persons & $\begin{array}{l}\text { https://doi.org/10.5258/SOTON/WP00645 } \\
\text { (WorldPop, 2018) }\end{array}$ & https://www.worldpop.org/ \\
\hline $\begin{array}{l}\text { Global Human } \\
\text { Settlement Layer } \\
\text { - Population } \\
\text { (GHS-POP) }\end{array}$ & $\begin{array}{l}1975 ; 1990 ; \\
2000 ; 2015\end{array}$ & Persons & $\begin{array}{l}\text { https://data.jrc.ec.europa.eu/dataset/ } \\
\text { jrc-ghsl-ghs_pop_gpw4_globe_r2015a } \\
\text { (last access: } 20 \text { May 2019) }\end{array}$ & https://ghsl.jrc.ec.europa.eu/ghs_pop.php \\
\hline World Population & 2013 & Persons & $\begin{array}{l}\text { https://doi.org/10.13140/RG.2.2.18213.14565 } \\
\text { (Nordstrand and Frye, 2014) }\end{array}$ & https://sites.google.com/ciesin. \\
\hline \multirow[t]{4}{*}{ Estimate (WPE) } & \multirow{2}{*}{2015} & Persons & $\begin{array}{l}\text { https://doi.org/10.13140/RG.2.2.16160.79367 } \\
\text { (Frye and Nordstrand, 2016a) }\end{array}$ & \multirow[t]{4}{*}{ columbia.edu/popgrid/find-data/esri } \\
\hline & & Pop. density & $\begin{array}{l}\text { https://doi.org/10.13140/RG.2.2.14857.70248 } \\
\text { (Frye and Nordstrand, 2016b) }\end{array}$ & \\
\hline & \multirow{2}{*}{2016} & Persons & $\begin{array}{l}\text { https://doi.org/10.13140/RG.2.2.12996.48007 } \\
\text { (Frye and Gilbert, 2018a) }\end{array}$ & \\
\hline & & Pop. density & $\begin{array}{l}\text { https://doi.org/10.13140/RG.2.2.21568.58885 } \\
\text { (Frye and Gilbert, 2018b) }\end{array}$ & \\
\hline $\begin{array}{l}\text { History Database of the } \\
\text { Global Environment } \\
\text { (HYDE) Population } \\
\text { Grids v3.2 }\end{array}$ & $\begin{array}{l}10000 \mathrm{BC} \\
\text { to } 2015\end{array}$ & Persons & $\begin{array}{l}\text { https://doi.org/10.17026/dans-25g-gez3 } \\
\text { (Klein Goldewijk, 2017) }\end{array}$ & $\begin{array}{l}\text { https://themasites.pbl.nl/tridion/en/ } \\
\text { themasites/hyde/download/index-2.html }\end{array}$ \\
\hline $\begin{array}{l}\text { High Resolution } \\
\text { Settlement Layer } \\
\text { (HRSL) }\end{array}$ & 2015 & Persons & $\begin{array}{l}\text { NA; data download at } \\
\text { https://ciesin.columbia.edu/data/hrsl/ } \\
\text { (last access: } 20 \text { May 2019) }\end{array}$ & https://ciesin.columbia.edu/data/hrsl/ \\
\hline $\begin{array}{l}\text { European GHS } \\
\text { Population Grid } \\
\text { (GHS-POP-EUROSTAT) }\end{array}$ & 2011 & Persons & $\begin{array}{l}\text { https://data.europa.eu/89h/jrc-ghsl- } \\
\text { ghs_pop_eurostat_europe_r2016a } \\
\text { (last access: } 20 \text { May 2019) }\end{array}$ & $\begin{array}{l}\text { https://data.jrc.ec.europa.eu/dataset/ } \\
\text { jrc-ghsl-ghs_pop_eurostat_europe_r2016a }\end{array}$ \\
\hline $\begin{array}{l}\text { Gridded Population } \\
\text { Mapping (Demobase) }\end{array}$ & $\begin{array}{l}1998 \text { to } \\
\text { present }\end{array}$ & Persons & $\begin{array}{l}\text { NA; data download at } \\
\text { https://www.census.gov/geographies/mapping- } \\
\text { files/time-series/demo/international- } \\
\text { programs/demobase.html (last access: } 20 \text { May 2019) }\end{array}$ & $\begin{array}{l}\text { https://www.census.gov/geographies/ } \\
\text { mapping-files/time-series/demo/ } \\
\text { international-programs/demobase.html }\end{array}$ \\
\hline
\end{tabular}

NA: not available. 
to estimate changes in built-up area using population as one of the explanatory variables, then one must not use GHS-POP (which uses built-up area). This necessitates that users become familiar with the ancillary data used in the production of the population grids and even those used, perhaps, in training datasets but not actually the modeling.

5. Analyzing change over time? If one's goal is to examine change over time in population distributions, one of the data products representing multiple years is most suitable. However, there may be differences in how different grids have been generated for specific years. In order to analyze change in population distributions, ideally a data product built from data layers representing the respective time period would be preferred. Data which represent only one time period and apply, say, nationallevel growth rates to derive data distributions for earlier time periods would be less amenable.

6. How have these datasets been used previously? Some of the data providers make available citation lists of publications from the providers' team or the broader user community that may provide some guidance for the novice user. For example, GPW, WorldPop, LandScan and others provide such lists, which are extremely useful as a collection of common applications in which those data have been used. Based on such lists, the user can explore whether prior use of the data products appears to be appropriate with regard to target applications and how these scenarios compare to their own study. These datasets are used in combination with other spatially rendered data, whether those data are thematically environmental, health-related or social in nature, leading to a wide array of usages. However, they are typically not combined with other data that are limited in their spatial specificity (such as historic census tables or national-level survey data).

This review is an attempt to shed light on underlying data considerations to raise the awareness of relative data quality concerns related to the described population data products. The data user community is encouraged to consider the described quality aspects and metadata carefully, before making decisions about any given data product's fitness for the target application. This can include the full assessment of the above aspects, the use of metadata and sensitivity analysis including running an analysis at different spatial resolutions or the comparison of analytical results using different population grids (see, e.g., Mondal and Tatem, 2012; Tatem et al., 2011) to understand and quantify the sensitivity of the study results.
There has been significant progress in the spatial rendering of population and related characteristics in the past 20 years, but persistent challenges remain. We depend on existing population grids that are created using ancillary data to provide hints for where people live or spend time. In an ideal world, the research community would also have access to detailed building footprint and height data for all structures, and know whether these structures are residential or commercial, if indeed they are occupied at all, to pair with population data. Future work will help to close these gaps by employing new high-resolution satellite technology as well as more reliable population surveys. This includes new and improved nighttime lights products (e.g., Visible Infrared Imaging Radiometer Suite, VIIRS, with respect to DMSP-OLS Nighttime Lights) that have been already successfully tested in urban mapping applications (Elvidge et al., 2017), as well as settlement data production (GHSL, GUF, as well as at Digital Globe, etc.) to further refine the available population grids.

It is important to note that since the first global population grid, the emphasis has been on producing grids of population counts and density rather than any other population attribute. While this emphasis has its obvious roots in the importance of population as a denominator, it also arises from the simple constraint that population is the most consistently measured variable across place and time (though not without historical exception). This community should accept it as a challenge to expand into other population attributes in the near future. Members of the POPGRID data collaborative are investing work in a number of emerging areas, including future population projections (Jones and O'Neill, 2016), population projections incorporating climate change impacts (Rigaud et al., 2018), near-real-time population modeling (Bharti et al., 2015), mobility mapping, population dynamics (Deville et al., 2014), increased temporal resolution (Batista e Silva et al., 2018) and working directly with national statistical offices to improve the spatial accuracy of census products (http://www.grid3.org/). These efforts often make use of novel data streams such as cell phone call detail records or social media data, or best practices in data collection using mobile devices. Finally, future work will be dedicated to improving the accuracy of population estimates, particularly in rural regions, where the reliability of existing data products is limited to date. 
Appendix A: Glossary of key terms

Population grid A spatial representation of either population counts or population density within a number

Spatial resolution of quadrilateral grid cells, covering a given extent on the Earth surface.

Analytical scale

The size of a grid cell used to represent the cell value (also called granularity).

Precision

Accuracy

Temporal resolution

The spatial scale (or level of aggregation) at which a given spatial

analysis will be performed; related to spatial resolution.

The degree of exactness of a measurement.

Refers to how close the measurements are to the true values.

The amount of time between two representations of the data covering the same area.

For remotely sensed data, it depends on the time a sensor revisits and

acquires data for the exact same location.

Currency

De facto population

The temporal proximity of the data of interest to a given point in time.

De jure population at the time of the enumeration.

Areal interpolation

Dasymetric mapping

The number of persons attributed to a geographical area based on their legal

or usual place of residence - regardless of whether they are present at the time of the enumeration.

The process of making estimates for a set of spatial units based on another

incongruent set of spatial units that can be partially or entirely overlapping.

Fitness for use

The process of spatially redistributing quantities through areal interpolation

using ancillary data associated with the variable of interest.

Modifiable areal unit

A concept to assess the characteristics and the level of relative quality/accuracy

of a given dataset in relation to a given purpose or to fulfill the user needs.

problem (MAUP)

A source of statistical bias due to arbitrary spatial aggregation of data potentially resulting in nonrepresentative results if the process of interest operates at different scales. 
Author contributions. SL, AEG, SBA, AdS, DB, SF, AJT, MP, $\mathrm{KM}, \mathrm{BB}$ and $\mathrm{ML}$ conceptualized this review article and formulated its vision. SL, AEG, SBA, DB and AdS structured the manuscript and developed contents of the various sections. SL, in collaboration with AEG, SBA and AdS, drafted the manuscript, with contributions from all coauthors. DB, AR, FRS, BB, CF, JC, AS, SF, MP and $\mathrm{KM}$ wrote and revised data product descriptions and provided insights on data product characteristics and underlying procedures. All authors have read and revised the manuscript. AEG and FRS created and SL revised Figs. 1 and 2; LP created Figs. 3 and 4.

Competing interests. The authors declare that they have no conflict of interest.

Acknowledgements. POPGRID has been supported by seed funding from the Columbia University Earth Institute's CrossCutting Initiatives and the Bill \& Melinda Gates Foundation. It is an element of the Group on Earth Observations (GEO) Human Planet Initiative (HPI) and is exploring linkages with key sustainable development data organizations and networks. Stefan Leyk is supported by the Eunice Kennedy Shriver National Institute of Child Health and Human Development of the National Institutes of Health under award number P2CHD066613. The content is solely the responsibility of the authors and does not necessarily represent the official views of the National Institutes of Health. Stefan Leyk and Deborah Balk are supported by the US National Science Foundation award number 1416860 to the City University of New York, the Population Council, the National Center for Atmospheric Research and the University of Colorado at Boulder. Andrea E. Gaughan, Forrest R. Stevens, Alessandro Sorichetta and Andrew J. Tatem are supported through funding from the Bill \& Melinda Gates Foundation investment ID OPP1134076 and Susana B. Adamo and Alex de Sherbinin by the Gates Foundation investment ID OPP1177328. Andrea E. Gaughan and Forrest R. Stevens are also supported through the NASA Land Cover and Land Use Change Program and the NASA GEO-Human Planet Program. We are grateful to the many individuals who produce, test and distribute these invaluable databases.

Brian Blankespoor appreciates the support of the World Bank and financing from DFID under the World Bank's Strategic Research Program "Big Data". The findings, interpretations and conclusions expressed in this paper are entirely those of the authors. They do not necessarily represent the views of the International Bank for Reconstruction and Development/World Bank and its affiliated organizations or those of the executive directors of the World Bank or the governments they represent.

Financial support. This research has been supported by the Eunice Kennedy Shriver National Institute of Child Health and Human Development (grant no. P2CHD066613); the National Science Foundation, Directorate for Social, Behavioral and Economic Sciences (grant no. 1416860); and the Bill \& Melinda Gates Foundation (grant nos. OPP1134076 and OPP1177328).
Review statement. This paper was edited by David Carlson and reviewed by Stephen Matthews and Tracy Kugler.

\section{References}

Agumya, A. and Hunter, G. F.: A Risk-Based Approach to Assessing the "Fitness for Use" of Spatial Data, URISA Journal, 11, 33-44, 1999.

Amrhein, C. G.: Searching for the Elusive Aggregation Effect: Evidence from Statistical Simulations, Environ. Plann. A, 27, 105119, https://doi.org/10.1068/a270105, 1995.

Arbia, G. and Petrarca, F.: Effects of MAUP on spatial econometric models, Letters in Spatial and Resource Sciences, 4, 173 https://doi.org/10.1007/s12076-011-0065-9, 2011.

Aubrecht, C., Gunasekera, R., Ungar, J., and Ishizawa, O.: Consistent yet adaptive global geospatial identification of urban-rural patterns: The iURBAN model, Remote Sens. Environ., 187, 230 240, https://doi.org/10.1016/j.rse.2016.10.031, 2016.

Azar, D., Graesser, J., Engstrom, R., Comenetz, J., Leddy, R. M., Schechtman, N. G., and Andrews, T.: Spatial refinement of census population distribution using remotely sensed estimates of impervious surfaces in Haiti, Int. J. Remote Sens., 31, 56355655, https://doi.org/10.1080/01431161.2010.496799, 2010.

Azar, D., Engstrom, R., Graesser, J., and Comenetz, J.: Generation of fine-scale population layers using multi-resolution satellite imagery and geospatial data, Remote Sens. Environ., 130, 219-232, https://doi.org/10.1016/j.rse.2012.11.022, 2013.

Balk, D.: More than a name: Why is Global Urban Population Mapping a GRUMPy proposition?, in: Global Mapping of Human Settlement: Experiences, Data Sets, and Prospects, edited by: Gamba, P. and Herold, M., Taylor and Francis, New York, 145161, 2009.

Balk, D., Pozzi, F., Yetman, G., Deichmann, U. and Nelson, A.: The distribution of people and the dimension of place: Methodologies to improve the global estimation of urban extents, International Society for Photogrammetry and Remote Sensing Proceedings of the Urban Remote Sensing Conference, Tempe, AZ, March 2005.

Balk, D., Deichmann, U., Yetman, G., Pozzi, F., Hay, S. I., and Nelson, A.: Determining Global Population Distribution: Methods, Applications and Data, ADV PARASIT, 62, 119-156, https://doi.org/10.1016/S0065-308X(05)62004-0, 2006.

Balk, D., Montgomery, M. R., McGranahan, G. and Todd, M.: Understanding the Impacts of Climate Change: Linking Satellite and Other Spatial Data with Population Data, in: Population Dynamics and Climate Change, edited by: Martine, G., Guzman, J. M., McGranahan, G., Schensul, D., and Tacoli, C., United Nations Population Fund and International Institute for the Environment and Development, New York, 206-217, 2009.

Batista e Silva, F., Marín Herrera, M. A., Rosina, K., Ribeiro Barranco, R., Freire, S., and Schiavina, M.: Analysing spatiotemporal patterns of tourism in Europe at high-resolution with conventional and big data sources, Tourism Manage., 68, 101-115, https://doi.org/10.1016/j.tourman.2018.02.020, 2018.

Bhaduri, B., Bright, E., Coleman, P., and Dobson, J.: LandScan: Locating people is what matters, Geoinformatics, 5, 34-37, 2002. 
Bhaduri, B. L., Bright, E. A., Rose, A. N., Liu, C., Urban, M. L., and Stewart, R. N.: Data Driven Approach for High Resolution Population Distribution and Dynamics Models, in: Proceedings of the Winter Simulation Conference 2014, Savannah, GA, USA, 7-10 December 2014, IEEE, https://doi.org/10.1109/WSC.2014.7019945, 2014.

Bharti, N., Lu, X., Bengtsson, L., Wetter, E., and Tatem, A. J.: Remotely measuring populations during a crisis by overlaying two data sources, Int. Health, 7, 90-98, https://doi.org/10.1093/inthealth/ihv003, 2015.

Birkin, M. and Clarke, M.: Synthesis - A Synthetic Spatial Information System for Urban and Regional Analysis: Methods and Examples, Environ. Plann. A, 20, 1645-1671, https://doi.org/10.1068/a201645, 1988.

Blankespoor, B., Dasgupta, S., and Lange, G.-M.: Mangroves as a protection from storm surges in a changing climate, AMBIO, 46, 478-491, https://doi.org/10.1007/s13280-016-0838-x, 2017.

Blankespoor, B., Kilic, T., Murray, S., and Wild, M.: Can remote sensing data complement or even replace the current sampling frames in household surveys in developing countries?, Washington, DC, 2018.

Bogaert, P.: Spatial prediction of categorical variables: the Bayesian maximum entropy approach, Stoch. Env. Res. Risk A, 16, 425448, https://doi.org/10.1007/s00477-002-0114-4, 2002.

Breiman, L.: Random Forests, Mach. Learn., 45, 5-32, https://doi.org/10.1023/a:1010933404324, 2001.

Cao, C. Y. and Lam, N.: Understanding the scale and resolution effects in remote sensing and GIS, in: Scale in remote sensing and GIS, edited by: Quattrochi, D. A. and Goodchild, M. F., Lewis Publishers, Boca Raton, FL, 1997.

CIESIN (Center for International Earth Science Information Network), IFPRI (International Food Policy Research Institute), The World Bank, and CIAT (Centro Internacional de Agricultura Tropical): Global Rural-Urban Mapping Project, Version 1 (GRUMPv1): Population Count Grid, NASA Socioeconomic Data and Applications Center (SEDAC), Palisades, NY, https://doi.org/10.7927/H4VT1Q1H, 2011a.

CIESIN, IFPRI, The World Bank, and CIAT: Global Rural-Urban Mapping Project, Version 1 (GRUMPv1): Population Density Grid, NASA Socioeconomic Data and Applications Center (SEDAC), Palisades, NY, https://doi.org/10.7927/H4R20Z93, $2011 b$.

CIESIN: Gridded Population of the World, Version 4 (GPWv4): Population Count, Revision 11, CIESIN, Columbia University, NASA Socioeconomic Data and Applications Center (SEDAC), Palisades, NY, https://doi.org/10.7927/H4JW8BX5, 2018a.

CIESIN: Gridded Population of the World, Version 4 (GPWv4): Population Count Adjusted to Match 2015 Revision of UN WPP Country Totals, Revision 11, NASA Socioeconomic Data and Applications Center (SEDAC), Palisades, NY, https://doi.org/10.7927/H4PN93PB, 2018b.

CIESIN: Gridded Population of the World, Version 4 (GPWv4): Population Density, Revision 11, NASA Socioeconomic Data and Applications Center (SEDAC), Palisades, NY, https://doi.org/10.7927/H49C6VHW, 2018c.

CIESIN: Gridded Population of the World, Version 4 (GPWv4): Population Density Adjusted to Match 2015 Revision UN WPP Country Totals, Revision 11, NASA Socioeconomic
Data and Applications Center (SEDAC), Palisades, NY, https://doi.org/10.7927/H4F47M65, 2018d.

Cohen, J. E., and Small, C.: Hypsographic demography: The distribution of human population by altitude, P. Natl. Acad. Sci. USA, 95, 14009-14014, https://doi.org/10.1073/pnas.95.24.14009, 1998.

Dasgupta, S., Laplante, B., Murray, S., and Wheeler, D.: Exposure of developing countries to sea-level rise and storm surges, Climatic Change, 106, 567-579, https://doi.org/10.1007/s10584010-9959-6, 2011.

de Bruin, S., Bregt, A., and van de Ven, M.: Assessing fitness for use: the expected value of spatial data sets, Int. J. Geogr. Inf. Sci., 15, 457-471, https://doi.org/10.1080/13658810110053116, 2001.

Deichmann, U.: A Review of Spatial Population Database Design and Modeling, UC Santa Barbara, National Center for Geographic Information and Analysis (NCGIA), Technical Report 96-3, 1996.

Deichmann, U. and Eklundh, L.: Global digital datasets for land degradation studies: a GIS approach, United Nations Environment Programme, Nairobi, 1991.

Deichmann, U., Meisner, C., Murray, S., and Wheeler, D.: The economics of renewable energy expansion in rural Sub-Saharan Africa. Energy Policy, 39, 215-227, https://doi.org/10.1016/j.enpol.2010.09.034, 2011.

de Sherbinin, A.: Remote Sensing and Socioeconomic Data Integration: Lessons from the NASA Socioeconomic Data and Applications Center, in: Integrating Scale in Remote Sensing and GIS, edited by: Quattrochi, D., Wentz, E., Lam, N. N., and Emerson, C., CRC Press, Boca Raton, FL, 2017.

Deville, P., Linard, C., Martin, S., Gilbert, M., Stevens, F. R., Gaughan, A. E., Blondel, V. D., and Tatem, A. J.: Dynamic population mapping using mobile phone data, P. Natl. Acad. Sci. USA, 111, 15888-15893, https://doi.org/10.1073/pnas.1408439111, 2014.

Devillers, R., Bédard, Y., Jeansoulin, R., and Moulin, B.: Towards spatial data quality information analysis tools for experts assessing the fitness for use of spatial data, Int. J. Geogr. Inf. Sci., 21, 261-282, https://doi.org/10.1080/13658810600911879, 2007.

Devillers, R., Stein, A., Bédard, Y., Chrisman, N., Fisher, P., and Shi, W.: Thirty Years of Research on Spatial Data Quality: Achievements, Failures, and Opportunities, T. GIS, 14, 387-400, https://doi.org/10.1111/j.1467-9671.2010.01212.x, 2010.

Dobson, J., Bright, E., Coleman, P., and Bhaduri, B.: LandScan: a global population database for estimating populations at risk, in: Remotely-Sensed Cities, edited by: Mesev, V., Taylor \& Francis, London, 2003.

Dobson, J. E., Bright, E. A., Coleman, P. R., Durfee, R. C., and Worley, B. A.: LandScan: A Global Population Database for Estimating Populations at Risk, Photogramm. Eng. Rem. S., 66, 849-857, 2000.

Doocy, S., Gorokhovich, Y., Burnham, G., Balk, D., and Robinson, C.: Tsunami mortality estimates and vulnerability mapping in Aceh, Indonesia, Am. J. Public Health, 97, S146-S151, https://doi.org/10.2105/AJPH.2006.095240, 2007.

Dong, N., Yang, X., Cai, H., and Xu, F.: Research on Grid Size Suitability of Gridded Population Distribution in Urban Area: A Case Study in Urban Area of Xuanzhou District, China, PLOS ONE, 
12, e0170830, https://doi.org/10.1371/journal.pone.0170830, 2017.

Doxsey-Whitfield, E., MacManus, K., Adamo, S. B., Pistolesi, L., Squires, J., Borkovska, O., and Baptista, S. R.: Taking Advantage of the Improved Availability of Census Data: A First Look at the Gridded Population of the World, Version 4, Papers in Applied Geography, 1, 226-234, https://doi.org/10.1080/23754931.2015.1014272, 2015.

Dunn, G., Johnson, G. D., Balk, D. L., and Sembajwe, G.:. Spatially varying relationships between risk factors and child diarrhea in West Africa, 2008-2013, Math. Popul. Stud., 1-26, https://doi.org/10.1080/08898480.2019.1592638, 2019.

Ehrlich, D., Melchiorri, M., Florczyk, A. J., Pesaresi, M., Kemper, T., Corbane, C., Freire, S., Schiavina, M., and Siragusa, A.: Remote Sensing Derived Built-Up Area and Population Density to Quantify Global Exposure to Five Natural Hazards over Time, Remote Sens., 10, 1378, https://doi.org/10.3390/rs10091378, 2018a.

Ehrlich, D., Kemper, T., Pesaresi, M., and Corbane, C.: Built-up area and population density: Two Essential Societal Variables to address climate hazard impact, Environ. Sci. Policy, 90, 73-82, https://doi.org/10.1016/j.envsci.2018.10.001, 2018b.

Eicher, C. L. and Brewer, C. A.: Dasymetric Mapping and Areal Interpolation: Implementation and Evaluation, Cartogr. Geogr. Inf. S., 28, 125-138, https://doi.org/10.1559/152304001782173727, 2001.

Elvidge, C. D., Baugh, K., Kihn, E., Kroehl, H., and Davis, E.: Mapping city lights with nighttime data from the DMSP operational linescan system, Photogramm. Eng. Rem. S., 63, 727-734, 1997.

Elvidge, C. D., Baugh, K., Zhizhin, M., Hsu, F. C., and Ghosh, T.: VIIRS night-time lights, Int. J. Remote Sens., 38, 5860-5879, https://doi.org/10.1080/01431161.2017.1342050, 2017.

Esch, T., Heldens, W., Hirner, A., Keil, M., Marconcini, M., Roth, A., Zeidler, J., Dech, S., and Strano, E.: Breaking new ground in mapping human settlements from space - The Global Urban Footprint, ISPRS J. Photogramm., 134, 30-42, https://doi.org/10.1016/j.isprsjprs.2017.10.012, 2017.

FGDC (Federal Geographic Data Committee): Geospatial Positioning Accuracy Standards, Part 3: National standard for spatial data accuracy, Subcommittee for Base Cartographic Data, FGDCSTD-007.3-1998, 25 pp., 1998.

Ferri, S., Syrris, V., Florczyk, A., Scavazzon, M., Halkia, M., and Pesaresi, M.: A new map of the European settlements by automatic classification of $2.5 \mathrm{~m}$ resolution SPOT data, in: Proceedings of the 2014 IEEE Geoscience and Remote Sensing Symposium, Quebec City, QC, Canada, 13-18 July 2014, 1160-1163, 2014.

Florczyk, A. J., Ferri, S., Syrris, V., Kemper, T., Halkia, M., Soille, P., and Pesaresi, M.: A New European Settlement Map From Optical Remotely Sensed Data, IEEE J. SEL. TOP. APPL., 9, 19781992, https://doi.org/10.1109/JSTARS.2015.2485662, 2016.

Flowerdew, R., Geddes, A., and Green, M.: Behaviour of Regression Models under Random Aggregation, in: Modelling scale in geographical information science, edited by: Tate, N. and Atkinson, P., Wiley, Chichester, 2001.

Fotheringham, S., Charlton, M., and Brunsdon, C.: The geography of parameter space: an investigation of spatial non-stationarity, Int. J. Geogr. Inf. Syst., 10, 605-627, https://doi.org/10.1080/02693799608902100, 1996.
Freire, S. and Halkia, M.: GHSL application in Europe: Towards new population grids, European Forum For Geography And Statistics, Krakow, Poland, 22--24 October 2014.

Freire, S., MacManus, K., Pesaresi, M., Doxsey-Whitfield, E., and Mills, J.: Development of New Open and Free Multi-Temporal Global Population Grids at $250 \mathrm{~m}$ Resolution, AGILE 2016, Helsinki, Finland, 14-17 June 2016.

Freire, S., Schiavina, M., Florczyk, A. J., MacManus, K., Pesaresi, M., Corbane, C., Borkovska, O., Mills, J., Pistolesi, L., Squires, J., and Sliuzas, R.: Enhanced data and methods for improving open and free global population grids: putting "leaving no one behind" into practice, Int. J. Digit. Earth, 1-17, https://doi.org/10.1080/17538947.2018.1548656, 2018.

Frye, C. and Gilbert, M.: World Population Estimated 2016, Esri, https://doi.org/10.13140/RG.2.2.12996.48007, 2018a.

Frye, C. and Gilbert, M.: World Population Estimated Density 2016, Esri, https://doi.org/10.13140/RG.2.2.21568.58885, 2018a.

Frye, C. and Nordstrand, E.: World Population Estimated 2015, Esri, https://doi.org/10.13140/RG.2.2.16160.79367, 2016a.

Frye, C. and Nordstrand, E.: World Population Estimated Density 2015, Esri, https://doi.org/10.13140/RG.2.2.14857.70248, 2016 b.

Frye, C., Wright, D. J., Nordstrand, E., Terborgh, C., and Foust, J.: Using Classified and Unclassified Land Cover Data to Estimate the Footprint of Human Settlement, Data Science Journal, 17, p. 20, https://doi.org/10.5334/dsj-2018-020, 2018.

Fung, I., John, J., Lerner, J., Matthews, E., Prather, M., Steele, L. P., and Fraser, P. J.: Three-dimensional model synthesis of the global methane cycle, J. Geophys. Res., 96, 13033-13065, https://doi.org/10.1029/91jd01247, 1991.

Gaughan, A. E., Stevens, F. R., Linard, C., Jia, P., and Tatem, A. J.: High Resolution Population Distribution Maps for Southeast Asia in 2010 and 2015, PLOS ONE, 8, e55882, https://doi.org/10.1371/journal.pone.0055882, 2013.

Gaughan, A. E., Stevens, F. R., Linard, C., Patel, N. N., and Tatem, A. J.: Exploring nationally and regionally defined models for large area population mapping, Int. J. Digit. Earth, 8, 989-1006, https://doi.org/10.1080/17538947.2014.965761, 2015.

Gaughan, A. E., Stevens, F. R., Huang, Z., Nieves, J. J., Sorichetta, A., Lai, S., Ye, X., Linard, C., Hornby, G. M., Hay, S. I., Yu, H., and Tatem, A. J.: Spatiotemporal patterns of population in mainland China, 1990 to 2010, Scientific Data, 3, 160005, https://doi.org/10.1038/sdata.2016.5, 2016.

Ge, Y., Jin, Y., Stein, A., Chen, Y., Wang, J., Wang, J., Cheng, Q., Bai, H., Liu, M., and Atkinson, P. M.: Principles and methods of scaling geospatial Earth science data, Earth-Sci. Rev., 197, 102897, https://doi.org/10.1016/j.earscirev.2019.102897, 2019.

GeoNames, http://www.geonames.org/ (last access: 20 May 2019), 2013.

Goodchild, M. F. and Lam, N. S. N.: Areal interpolation: a variant of the traditional spatial problem, Geo-Processing, 1, 297-312, 1980.

Gunasekera, R., Ishizawa, O., Aubrecht, C., Blankespoor, B., Murray, S., Pomonis, A., and Daniell, J.: Developing an adaptive global exposure model to support the generation of country disaster risk profiles, Earth-Sci. Rev., 150, 594-608, https://doi.org/10.1016/j.earscirev.2015.08.012, 2015.

Guptill, S. C. and Morrison, J. L. (Eds.): Elements of spatial data quality, Elsevier, Oxford, UK, 2013. 
Harvey, J. T.: Estimating census district populations from satellite imagery: Some approaches and limitations, Int. J. Remote Sens., 23, 2071-2095, https://doi.org/10.1080/01431160110075901, 2002.

Hay, S. I., Guerra, C. A., Tatem, A. J., Noor, A. M., and Snow, R. W.: The global distribution and population at risk of malaria: past, present, and future, Lancet Infect. Dis., 4, 327-336, https://doi.org/10.1016/S1473-3099(04)01043-6, 2004.

HERE, https://www.here.com/products/mapping/map-data, last access: 20 May 2019.

Iimi, A., Ahmed, A. K. F., Anderson, E. C., Diehl, A. S., Maiyo, L., Peralta Quiros, T., and Rao, K. S.: New rural access index: main determinants and correlation to poverty, World Bank Group, Washington, DC, 2016.

Islam, M. S., Oki, T., Kanae, S., Hanasaki, N., Agata, Y., and Yoshimura, K.: A grid-based assessment of global water scarcity including virtual water trading, Water Resour. Manag., 21, 19, https://doi.org/10.1007/s11269-006-9038-y, 2006.

Ivánová, I., Morales, J., de By, R. A., Beshe, T. S., and Gebresilassie, M. A.: Searching for spatial data resources by fitness for use, J. Spat. Sci., 58, 15-28, https://doi.org/10.1080/14498596.2012.759087, 2013.

Jenness, J. S.: Calculating landscape surface area from digital elevation models, Wildlife Soc. B., 32, 829-839, 2004.

Jones, B. and O'Neill, B. C.: Spatially explicit global population scenarios consistent with the Shared Socioeconomic Pathways, Environ. Res. Lett., 11, 084003, https://doi.org/10.1088/17489326/11/8/084003, 2016.

Jones, K. E., Patel, N. G., Levy, M. A., Storeygard, A., Balk, D., Gittleman, J. L., and Daszak, P.: Global trends in emerging infectious diseases, Nature, 451, 990-993, https://doi.org/10.1038/nature06536, 2008.

Klein Goldewijk, K.: Anthropogenic land-use estimates for the Holocene; HYDE 3.2, DANS, https://doi.org/10.17026/dans25g-gez3, 2017.

Klein Goldewijk, K., Beusen, A., and Janssen, P.: Long-term dynamic modeling of global population and built-up area in a spatially explicit way: HYDE 3.1, Holocene, 20, 565-573, https://doi.org/10.1177/0959683609356587, 2010.

Klein Goldewijk, K., Beusen, A., van Drecht, G., and de Vos, M.: The HYDE 3.1 spatially explicit database of human-induced global land-use change over the past 12,000 years, Global Ecol. Biogeogr., 20, 73-86, https://doi.org/10.1111/j.14668238.2010.00587.x, 2011.

Klein Goldewijk, K., Beusen, A., Doelman, J., and Stehfest, E.: Anthropogenic land use estimates for the Holocene - HYDE 3.2, Earth Syst. Sci. Data, 9, 927-953, https://doi.org/10.5194/essd9-927-2017, 2017.

Koch, J., Schaldach, R., and Köchy, M.: Modeling the impacts of grazing land management on land-use change for the Jordan River region, Global Planet. Change, 64, 177-187, https://doi.org/10.1016/j.gloplacha.2008.09.005, 2008.

Leyk, S. and Uhl, J. H.: HISDAC-US, historical settlement data compilation for the conterminous United States over 200 years, Scientific Data, 5, 180175, https://doi.org/10.1038/sdata.2018.175, 2018.
Leyk, S., Nagle, N. N., and Buttenfield, B. P.: Maximum Entropy Dasymetric Modeling for Demographic Small Area Estimation, Geogr. Anal, 45, 285-306, https://doi.org/10.1111/gean.12011, 2013.

Leyk, S., Ruther, M., Buttenfield, B. P., Nagle, N. N., and Stum, A. K.: Modeling residential developed land in rural areas: A sizerestricted approach using parcel data, Appl. Geogr., 47, 33-45, https://doi.org/10.1016/j.apgeog.2013.11.013, 2014.

Leyk, S., Uhl, J. H., Balk, D., and Jones, B.: Assessing the accuracy of multi-temporal built-up land layers across rural-urban trajectories in the United States, Remote Sens. Environ., 204, 898-917, https://doi.org/10.1016/j.rse.2017.08.035, 2018.

Linard, C. and Tatem, A. J.: Large-scale spatial population databases in infectious disease research, Int. J. Health Geogr., 11, 7, https://doi.org/10.1186/1476-072x-11-7, 2012.

Liverman, D., Moran, E., Rindfuss, R., and Stern, P. (Eds.): People and Pixels: Linking Remote Sensing and Social Science, National Research Council, The National Academies Press, Washington, DC, 1998.

Lloyd, C. T., Sorichetta, A., and Tatem, A. J.: High resolution global gridded data for use in population studies, Scientific Data, 4, 170001, https://doi.org/10.1038/sdata.2017.1, 2017.

MacDonald Dettwiler and Associates (MDA): https: //landscape6.arcgis.com/arcgis/rest/services/World_Land_ Cover_30m_BaseVue_2013/ImageServer (last access: 20 May 2019), 2017.

Maclaurin, G., Leyk, S., and Hunter, L. M.: Understanding the combined impacts of aggregation and spatial non-stationarity: The case of migration-environment associations in rural South Africa, T. GIS, 19, 877-895, https://doi.org/10.1111/tgis.12134, 2015.

Martin, D.: An assessment of surface and zonal models of population, Int. J. Geogr. Inf. Syst., 10, 973-989, https://doi.org/10.1080/02693799608902120, 1996.

Martin, D. and Bracken, I.: Techniques for modelling populationrelated raster databases, Environ. Plann. A, 23, 1069-1075, https://doi.org/10.1068/a231069, 1991.

McDonald, R. I., Green, P., Balk, D., Fekete, B. M., Revenga, C., Todd, M., and Montgomery, M.: Urban growth, climate change, and freshwater availability, P. Natl. Acad. Sci. USA, 108, 63126317, https://doi.org/10.1073/pnas.1011615108, 2011.

McGranahan, G., Balk, D., and Anderson, B.: The rising tide: assessing the risks of climate change and human settlements in low elevation coastal zones, Environ. Urban., 19, 17-37, https://doi.org/10.1177/0956247807076960, 2007.

Melchiorri, M., Pesaresi, M., Florczyk, A. J., Corbane, C., and Kemper, T.: Principles and Applications of the Global Human Settlement Layer as Baseline for the Land Use Efficiency Indicator-SDG 11.3.1, ISPRS Int. J. Geo-Inf., 8, 96, https://doi.org/10.3390/ijgi8020096, 2019.

Mennis, J.: Generating Surface Models of Population Using Dasymetric Mapping, Prof. Geogr., 55, 31-42, https://www. tandfonline.com/doi/full/10.1111/0033-0124.10042, 2003.

Mennis, J.: Dasymetric Mapping for Estimating Population in Small Areas, Geography Compass, 3, 727-745, https://doi.org/10.1111/j.1749-8198.2009.00220.x, 2009.

Mennis, J. and Hultgren, T.: Intelligent Dasymetric Mapping and Its Application to Areal Interpolation, Cartogr. Geogr. Inf. Sc., 33, 179-194, https://doi.org/10.1559/152304006779077309, 2006. 
Mondal, P. and Tatem, A. J.: Uncertainties in Measuring Populations Potentially Impacted by Sea Level Rise and Coastal Flooding, PLOS ONE, 7, e48191, https://doi.org/10.1371/journal.pone.0048191, 2012.

Montello, D. R.: Scale in geography, in: International Encyclopedia of the Social and Behavioral Sciences, edited by: Smelser, N. J. and Baltes, B., Pergamon, Oxford, 13501-13504, 2001.

Mrozinski, R. D. and Cromley, R. G.: Singly- and DoublyConstrained Methods of Areal Interpolation for Vectorbased GIS, T. GIS, 3, 285-301, https://doi.org/10.1111/14679671.00022, 1999.

Myers, R. J.: Errors and bias in the reporting of ages in census data, in: Readings in population research methodology. Volume 1: Basic Tools, edited by: Bogue, D. J., Arriaga, E. E., Anderton, D. L., and Rumsey, G. W., Social Development Center, Chicago, Illinois, 1993.

Nagle, N. N., Buttenfield, B. P., Leyk, S., and Speilman, S.: Dasymetric Modeling and Uncertainty, Ann. Assoc. Am. Geogr., 104, 80-95, https://doi.org/10.1080/00045608.2013.843439, 2014.

Nieves, J. J., Stevens, F. R., Gaughan, A. E., Linard, C., Sorichetta, A., Hornby, G., Patel, N. N., and Tatem, A. J.: Examining the correlates and drivers of human population distributions across lowand middle-income countries, J. R. Soc. Interface, 14, 20170401, https://doi.org/10.1098/rsif.2017.0401, 2017.

Nordhaus, W. D.: Geography and macroeconomics: New data and new findings, P. Natl. Acad. Sci. USA, 103, 3510-3517, https://doi.org/10.1073/pnas.0509842103, 2006.

Nordstrand, E. and Frye, C.: World Population Estimate, Esri, https://doi.org/10.13140/RG.2.2.18213.14565, 2014.

Openshaw, S.: The modifiable areal unit problem, Geo Books, Norwick, Norfolk, 1983.

Openshaw, S. and Taylor, P. J.: The modifiable areal unit problem, in: Quantitative Geography: A British View, edited by: Wrigley, N. and Bennett, R., Routledge and Kegan Paul, London, 1981.

OpenStreetMap Foundation (OSMF): https://www.openstreetmap. org (last access: 20 May 2019), 2015.

Parish, E. S., Kodra, E., Steinhaeuser, K., and Ganguly, A. R.: Estimating future global per capita water availability based on changes in climate and population, Comput. Geosci., 42, 79-86, https://doi.org/10.1016/j.cageo.2012.01.019, 2012.

Pawitan, G. and Steel, D. G.: Exploring a Relationship Between Aggregate and Individual Levels Spatial Data Through Semivariogram Models, Geogr. Anal., 38, 310-325, https://doi.org/10.1111/j.1538-4632.2006.00688.x, 2006.

Pesaresi, M., Huadong, G., Blaes, X., Ehrlich, D., Ferri, S., Gueguen, L., Halkia, M., Kauffmann, M., Kemper, T., Lu, L., Marin-Herrera, M. A., Ouzounis, G. K., Scavazzon, M., Soille, P., Syrris, V., and Zanchetta, L.: A Global Human Settlement Layer From Optical HR/VHR RS Data: Concept and First Results, IEEE J. Sel. Top. Appl., 6, 2102-2131, https://doi.org/10.1109/JSTARS.2013.2271445, 2013.

Pesaresi, M., Ehrlich, D., Ferri, S., Florczyk, A., Freire, S. C., Halkia, S., Julea, A. M., Kemper, T., Soille, P., and Syrris, V.: Operating procedure for the production of the Global Human Settlement Layer from Landsat data of the epochs 1975, 1990, 2000, and 2014, JRC Technical Report EUR 27741 EN, 2016 a.

Pesaresi, M., Ehrlich, D., Florczyk, A. J., Freire, S., Julea, A., Kemper, T., and Syrris, V.: The global human settlement layer from landsat imagery, in: 2016 IEEE In- ternational Geoscience and Remote Sensing Symposium (IGARSS), Beijing, China, 10-15 July 2016, IEEE, 7276-7279, https://doi.org/10.1109/IGARSS.2016.7730897, $2016 \mathrm{~b}$.

Piantadosi, S., Byar, D. P., and Green, S. B.: The ecological fallacy, Am. J. Epidemiol., 127, 893-904, https://doi.org/10.1093/oxfordjournals.aje.a114892, 1988.

POPGRID: https://www.popgrid.org/ (last access: 20 May 2019), 2018.

Potere, D., Schneider, A., Angel, S., and Civco, D. L.: Mapping urban areas on a global scale: which of the eight maps now available is more accurate?, Int. J. Remote Sens., 30, 6531-6558, https://doi.org/10.1080/01431160903121134, 2009.

Potter, J. E. and Ordóñez, M. G.: The Completeness of Enumeration in the 1973 Census of the Population of Colombia, Popul. Index, 42, 377-403, https://doi.org/10.2307/2734458, 1976.

Reed, F. J., Gaughan, A. E., Stevens, F. R., Yetman, G., Sorichetta, A., and Tatem, A. J.: Gridded Population Maps Informed by Different Built Settlement Products, Data, 3, 33, https://doi.org/10.3390/data3030033, 2018.

Reibel, M. and Bufalino, M. E.: Street-Weighted Interpolation Techniques for Demographic Count Estimation in Incompatible Zone Systems, Environ. Plann. A, 37, 127-139, https://doi.org/10.1068/a36202, 2005.

Rigaud, K. K., de Sherbinin, A., Jones, B., Bergmann, J., Clement, V., Ober, K., Schewe, J., Adamo, S., McCusker, B., Heuser, S., and Midgley, A.: Groundswell: Preparing for Internal Climate Migration, The World Bank, Washington, DC, 2018.

Roberts, M., Blankespoor, B., Deuskar, C., and Stewart, B.: Urbanization and Development: Is Latin America and the Caribbean Different from the Rest of the World?, World Bank Group, Washington, DC, 2017.

Schroeder, J. P.: Target-density weighting interpolation and uncertainty evaluation for temporal analysis of census data, Geogr. Anal., 39, 311-335, https://doi.org/10.1111/j.15384632.2007.00706.x, 2007.

See, L., Fritz, S., Perger, C., Schill, C., McCallum, I., Schepaschenko, D., Duerauer, M., Sturn, T., Karner, M., Kraxner, F., and Obersteiner, M.: Harnessing the power of volunteers, the internet and Google Earth to collect and validate global spatial information using Geo-Wiki, Technol. Forecast. Soc., 98, 324-335, https://doi.org/10.1016/j.techfore.2015.03.002, 2015.

Semenov-Tian-Shansky, B.: Russia: Territory and Population: A Perspective on the 1926 Census, Geogr. Rev., 18, 616-640, https://doi.org/10.2307/207951, 1928.

Simarro, P. P., Cecchi, G., Franco, J. R., Paone, M., Fèvre, E. M., Diarra, A., Ruiz Postigo, J. A., Mattioli, R. C., and Jannin, J. C.: Risk for Human African Trypanosomiasis, Central Africa, 2000-2009, Emerg. Infect. Dis., 17, 2322-2324, https://doi.org/10.3201/eid1712.110921, 2011.

Sinha, P., Gaughan, A. E., Stevens, F. R., Nieves, J. J., Sorichetta, A., and Tatem, A. J.: Assessing the spatial sensitivity of a random forest model: Application in gridded population modeling, Comput. Environ. Urban, 75, 132-145, https://doi.org/10.1016/j.compenvurbsys.2019.01.006, 2019.

Small, C., Pozzi, F., and Elvidge, C. D.: Spatial analysis of global urban extent from DMSP-OLS night lights, Remote Sens. Environ., 96, 277-291, https://doi.org/10.1016/j.rse.2005.02.002, 2005 . 
Snow, R. W., Craig, M., Deichmann, U., and Marsh, K.: Estimating mortality, morbidity and disability due to malaria among Africa's non-pregnant population, B. World Health Organ., 77, 624-640, 1999.

Sorichetta, A., Hornby, G. M., Stevens, F. R., Gaughan, A. E., Linard, C., and Tatem, A. J.: High-resolution gridded population datasets for Latin America and the Caribbean in 2010, 2015, and 2020, Scientific Data, 2, 150045, https://doi.org/10.1038/sdata.2015.45, 2015.

Sorichetta, A., Bird, T. J., Ruktanonchai, N. W., zu ErbachSchoenberg, E., Pezzulo, C., Tejedor, N., Waldock, I. C., Sadler, J. D., Garcia, A. J., Sedda, L., and Tatem, A. J.: Mapping internal connectivity through human migration in malaria endemic countries, Scientific Data, 3, 160066, https://doi.org/10.1038/sdata.2016.66, 2016.

Steel, D. G. and Holt, D.: Rules for Random Aggregation, Environ. Plann. A, 28, 957-978, https://doi.org/10.1068/a280957, 1996.

Stevens, F. R., Gaughan, A. E., Linard, C., and Tatem, A. J.: Disaggregating Census Data for Population Mapping Using Random Forests with Remotely-Sensed and Ancillary Data, PLOS ONE, 10, e0107042, https://doi.org/10.1371/journal.pone.0107042, 2015.

Taramelli, A., Melelli, L., Pasqui, M., and Sorichetta, A.: Modelling risk hurricane elements in potentially affected areas by a GIS system, Geomat. Nat. Haz. Risk, 14, 349-373, https://doi.org/10.1080/19475705.2010.532972, 2010.

Tatem, A. J.: Mapping the denominator: spatial demography in the measurement of progress, Int. Health, 6, 153-155, https://doi.org/10.1093/inthealth/ihu057, 2014.

Tatem, A. J.: WorldPop, open data for spatial demography, Scientific Data, 4, 170004, https://doi.org/10.1038/sdata.2017.4, 2017.

Tatem, A. J., Campiz, N., Gething, P. W., Snow, R. W., and Linard, C.: The effects of spatial population dataset choice on estimates of population at risk of disease, Popul. Health Metr., 9, 4, https://doi.org/10.1186/1478-7954-9-4, 2011.

Tayi, G. K. and Ballou, D. P.: Examining data quality, Commun. ACM, 41, 54-57, https://doi.org/10.1145/269012.269021, 1998.

Thomson, D. R., Stevens, F. R., Ruktanonchai, N. W., Tatem, A. J., and Castro, M. C.: GridSample: an R package to generate household survey primary sampling units (PSUs) from gridded population data, Int. J. Health Geogr., 16, 25, https://doi.org/10.1186/s12942-017-0098-4, 2017.

Tiecke, T.: Open population datasets and open challenges, available at: https://code.fb.com/connectivity/ open-population-datasets-and-open-challenges/ (last access: 20 May 2019), 2016.

Tiecke, T. G., Liu, X., Zhang, A., Gros, A., Li, N., Yetman, G., and Dang, H.-A. H.: Mapping the world population one building at a time, available at: https://arxiv.org/abs/1712.05839 (last access: 20 May 2019), 2017.

Tobler, W., Deichmann, U., Gottsegen, J., and Maloy, K.: The Global Demography Project, National Center for Geographic Information and Analysis, Department of Geography, University of California, Santa Barbara CA, Technical Report TR-95-6, 67 pp., 1995.

Tobler, W., Deichmann, U., Gottsegen, J., and Maloy, K.: World population in a grid of spherical quadrilaterals, International Journal of Population Geogra- phy, 3, 203-225, https://doi.org/10.1002/(SICI)10991220(199709)3:3<203::AID-IJPG68>3.0.CO;2-C, 1997.

Uchida, H. and Nelson, A.: Agglomeration Index: Towards a New Measure of Urban Concentration, World Bank, Washington, DC, USA, 2009.

Uhl, J. H., Zoraghein, H., Leyk, S., Balk, D., Corbane, C., Syrris, V., and Florczyk, A. J.: Exposing the urban continuum: Implications and cross-comparison from an interdisciplinary perspective, Int. J. Digit. Earth, 1-23, https://doi.org/10.1080/17538947.2018.1550120, 2018.

United Nations: Handbook on Geospatial Infrastructure in Support of Census Activities New York, United Nations, Department of Economic and Social Affairs, Statistics Division, Series F 103, 2009.

United Nations: World Population Prospects 2019: Highlights (ST/ESA/SER.A/423), United Nations, Department of Economic and Social Affairs, Population Division, 2019.

United Nations: World Population Prospects after 1950, UN, Department for Economic and Social Affairs, Population Division, New York, xxxiii, 965 pp., ISBN: 978-92-1-151465-0, 2009.

U.S. Census Bureau: International Programs, available at: https: //www.census.gov/programs-surveys/international-programs/ about/global-mapping.html, last access: 12 November 2018.

Waller, L. and Gotway, C.: Applied Spatial Statistics for Public Health Data, Wiley, Hoboken, NJ, 2004.

Wardrop, N. A., Jochem, W. C., Bird, T. J., Chamberlain, H. R., Clarke, D., Kerr, D., Bengtsson, L., Juran, S., Seaman, V., and Tatem, A. J.: Spatially disaggregated population estimates in the absence of national population and housing census data, P. Natl. Acad. Sci. USA, 115, 3529-3537, https://doi.org/10.1073/pnas.1715305115, 2018.

Weber, E. M., Seaman, V. Y., Stewart, R. N., Bird, T. J., Tatem, A. J., McKee, J. J., Bhaduri, B. L., Moehl, J. J., and Reith, A. E.: Census-independent population mapping in northern Nigeria, Remote Sens. Environ., 204, 786-798, https://doi.org/10.1016/j.rse.2017.09.024, 2018.

Wesolowski, A., Buckee, C. O., Bengtsson, L., Wetter, E., Lu, X., and Tatem, A. J.: Commentary: Containing the Ebola Outbreak - the Potential and Challenge of Mobile Network Data, PLOS Currents, 6, https://doi.org/10.1371/currents.outbreaks. 0177e7fcf52217b8b634376e2f3efc5e, 2014.

Wickham, J. D., Stehman, S. V., Gass, L., Dewitz, J., Fry, J. A., and Wade, T. G.: Accuracy assessment of NLCD 2006 land cover and impervious surface, Remote Sens. Environ., 130, 294-304, https://doi.org/10.1016/j.rse.2012.12.001, 2013.

Wong, D.: The modifiable areal unit problem (MAUP), in: The SAGE handbook of spatial analysis, edited by: Fotheringham, A. and Rogerson, P., SAGE, Los Angeles, USA, 2009.

Wong, D. W. S.: The Reliability of Using the Iterative Proportional Fitting Procedure, Prof. Geogr., 44, 340-348, https://doi.org/10.1111/j.0033-0124.1992.00340.x, 1992.

World Bank: Measuring rural access: using new technologies, World Bank Group, Washington, DC, available at: http: //documents.worldbank.org/curated/en/367391472117815229/ Measuring-ruralaccess-using-new-technologies (last access: 20 May 2019), 2016 (in English).

WorldPop (School of Geography and Environmental Science, University of Southampton; Department of Geography and Geosciences, University of Louisville; Département de Géo- 
graphie, Université de Namur) and CIESIN (Center for International Earth Science Information Network), Columbia University: Global High Resolution Population Denominators Project - Funded by The Bill and Melinda Gates Foundation (OPP1134076), https://www.worldpop.org/doi/10.5258/ SOTON/WP00645, 2018

Wright, J. K.: A Method of Mapping Densities of Population: With Cape Cod as an Example, Geogr. Rev., 26, 103-110, 1936.

Wu, S.-s., Qiu, X., and Wang, L.: Population Estimation Methods in GIS and Remote Sensing: A Review, GISci. Remote Sens., 42, 80-96, https://doi.org/10.2747/1548-1603.42.1.80, 2005.
Zandbergen, P. A. and Ignizio, D. A.: Comparison of Dasymetric Mapping Techniques for Small-Area Population Estimates, Cartogr. Geogr. Inf. Sc., 37, 199-214, https://doi.org/10.1559/152304010792194985, 2010.

Zoraghein, H., Leyk, S., Ruther, M., and Buttenfield, B. P.: Exploiting temporal information in parcel data to refine small area population estimates, Comput. Environ. Urban, 58, 19-28, https://doi.org/10.1016/j.compenvurbsys.2016.03.004, 2016. 